Article

\title{
Numerical Analysis of a Moderate Fire inside a Segment of a Subway Station
}

\author{
Rodrigo Díaz ${ }^{1}$, Hui Wang ${ }^{1,2} \mathbb{D}$, Herbert Mang ${ }^{1,2}$, Yong Yuan ${ }^{2}$ and Bernhard Pichler ${ }^{1, * \mathbb{C}}$ \\ 1 Institute for Mechanics of Materials and Structures, TU Wien-Vienna University of Technology, \\ Karlsplatz 13/202, 1040 Vienna, Austria; rodrigo_diaz92@hotmail.com (R.D.); \\ hui.wang@tuwien.ac.at (H.W.); herbert.mang@tuwien.ac.at (H.M.) \\ 2 College of Civil Engineering, Tongji University, Shanghai 200092, China; yuany@tongji.edu.cn \\ * Correspondence: bernhard.pichler@tuwien.ac.at
}

Received:25 September 2018; Accepted: 26 October 2018; Published: 1 November 2018

\begin{abstract}
A 1:4 scaled fire test of a segment of a subway station is analyzed by means of three-dimensional Finite Element simulations. The first $30 \mathrm{~min}$ of the test are considered to be representative of a moderate fire. Numerical sensitivity analyses are performed. As regards the thermal boundary conditions, a spatially uniform surface temperature history and three different piecewise uniform surface temperature histories are used. As regards the material behavior of concrete, a temperature-independent linear-elastic model and a temperature-dependent elasto-plastic model are used. Heat transfer within the reinforced concrete structure is simulated first. The computed temperature evolutions serve as input for thermomechanical simulations of the fire test. Numerical results are compared with experimental measurements. It is concluded that three sources of uncertainties render the numerical simulation of fire tests challenging: possible damage of the structure prior to testing, the actual distribution of the surface temperature during the test and the time-dependent high-temperature behavior of concrete. In addition, the simulations underline that even a moderate fire represents a severe load case, threatening the integrity of the reinforced concrete structure. Tensile cracking is likely to happen at the inaccessible outer surface of the underground structure. Thus, careful inspection is recommended even after non-catastrophic fires.
\end{abstract}

Keywords: thermomechanical analysis; moderate fire; finite element simulations

\section{Introduction}

Structural engineers are interested in the load-carrying behavior of reinforced concrete (RC) structures exposed to fires. Research on the high-temperature performance of RC structures involves the entire field of engineering sciences, dealing with the thermal degradation of concrete [1-3], the underlying hygro-thermo-chemo-mechanical couplings [4,5], transport of heat and moisture [6-8], the transient thermal strain of concrete [9-11], also referred to as load-induced thermal strains [12], spalling of concrete [13-15], the interaction between concrete and steel rebars [16-18] and the interaction between different $\mathrm{RC}$ elements that are connected to form RC structures.

These interactions were studied by means of experiments and/or numerical analyses. As for structural elements, related studies have been devoted to normal-strength concrete columns with circular cross-sections [19], high-strength concrete columns with quadratic cross-sections [20-22], RC beams, either unprotected [23] or protected by fiber-reinforced polymer laminates [24], high-performance self-compacting concrete slabs with superabsorbent polymers and polypropylene fibers [25], T-shaped beams, made of high-strength reinforced concrete [26] and prefabricated RC segments for linings of shield tunnels [27]. As for entire RC structures, testing and/or simulations were carried out for RC slabs resting on steel frames [28], slab-column connections, made of 
reinforced concrete [29], composite slabs with, as well as without a supporting secondary beam [30], RC frame structures [31-33], the Channel Tunnel between France and the United Kingdom [2,13], other monolithic tunnel linings with cross-sections in the form of a segment of a circle $[34,35]$, of an ellipse [36] and in the form of a double box [37], a segmental tunnel ring of a metro tunnel [38] and the twin-tube cross-section of the immersed tunnel of the Hong Kong-Zhuhai-Macao-Bridge [39].

The present study refers to another interesting structure: a segment of a subway station. It represents a statically indeterminate RC structure, consisting of a top slab, a bottom slab, two lateral walls and two columns connecting the top and bottom slabs. A 1:4-scale model of this structure was tested by Lu et al. [40]. Before the fire test, the structure was subjected to mechanical loads, simulating a combination of in situ ground pressure, water pressure, as well as dead and live loads that occur in the tunnel under service conditions. These loads were kept constant throughout the subsequent fire test. During this test, the temperature of the air in the interior of the tested structure was increased according to a prespecified temperature history. The performance of the structure was monitored during the test by means of temperature sensors ("thermocouples") and strain gauges.

The aforementioned studies refer to catastrophic fire scenarios with maximum temperatures typically larger than $1000{ }^{\circ} \mathrm{C}$. Such disasters are fortunately rare events, whereas moderate fires happen much more frequently [41]. Thereby, the expression "moderate fire" refers to a scenario that develops initially like a catastrophic fire disaster, but is stopped by fire fighters early enough so that the structure is not damaged severely. Consequently, moderate fires are, at least from the structural viewpoint, non-catastrophic events. Because of their frequency, however, they deserve more attention from structural engineers. This is setting the scene for the present study.

Here, the first $30 \mathrm{~min}$ of the fire test by Lu et al. [40] are analyzed, based on three-dimensional Finite Element simulations using the commercial software Abaqus FEA 2016 [42]. This period of time is chosen since it is representative of a moderate fire. Heat transfer in the analyzed reinforced concrete structure is simulated first. The obtained temperature field histories are subsequently used as the basis for thermomechanical analyses of the load-carrying behavior of the tested structure during the fire test. The specific challenges of these two types of simulations refer to:

- the boundary conditions required for the analysis of the heat transfer problem and

- the material behavior of concrete, subjected to both mechanical loading and elevated temperatures.

Both items involve significant uncertainties. This provides the motivation for corresponding sensitivity analyses. They are described in the following.

Regarding the thermal boundary conditions, the first approach is based on prescribing one specific temperature history at the entire interior surface of the structure. The prescribed temperature evolution is set equal to the average of the readings of two temperature sensors, which were positioned at a distance of $2 \mathrm{~mm}$ from the heated surface. One sensor was located inside the top slab and the other one inside the right wall. In the second approach, the heated inner surface of the structure is subdivided into three sub-regions. Each of them is subjected to a uniform distribution of a specific temperature history. The three required temperature histories are selected, in the context of model updating, such that satisfactory agreement between simulation results and temperature measurements is obtained.

The material behavior of concrete is simulated as either temperature-independent and linear-elastic or temperature-dependent and elasto-plastic. For the latter simulation, the Concrete Damaged Plasticity (CDP) model of Abaqus FEA is used [42]. Thereby, the nonlinear constitutive behavior of concrete and steel, including their temperature-induced degradation, agree with the recommendations by the Eurocode 2 [43] and the fib Model Code [44].

Results obtained from the described structural sensitivity analyses will allow for an assessment of the relative importance of thermal boundary conditions and the material behavior of concrete. This is important for structural engineers whose research efforts are devoted to dealing with large uncertainties that still exist in this research area. In addition, the simulation results will allow for providing recommendations regarding the inspection of RC structures after non-catastrophic fire events. 
The present paper is organized as follows. In Section 2, experimental data from the scaled fire test of an underground reinforced concrete structure are presented. In Section 3, transient simulations of the non-stationary heat transfer in the reinforced concrete structure are described. This includes sensitivity analyses with two different types of thermal boundary conditions. In Section 4, the load-carrying behavior of the structure during the fire test is analyzed, based on thermomechanical numerical simulations. This includes sensitivity analyses with two different types of material models for concrete. In addition, the two temperature field histories of Section 3 serve as input. Thus, altogether, four structural simulations are described. The comparison of simulation results and experimental measurements focuses on two time instants: (i) the time instant right before the fire test (at that time, the structure was already subjected to mechanical loading) and (ii) $30 \mathrm{~min}$ after the start of the fire test. Finally, Section 5 contains a summary and conclusions.

\section{Experimental Results from a Scaled Fire Test}

The tested structure was inspired by a three-span two-floor reinforced concrete frame, as is frequently used in China for subway lines; see Figure 1. The height of the floors amounts to $5950 \mathrm{~mm}$ and $6190 \mathrm{~mm}$, respectively, the total internal span to $20,700 \mathrm{~mm}$ and the cross-sectional area of the columns, which subdivide the frame into three cells, to $1200 \mathrm{~mm} \times 800 \mathrm{~mm}$. In the real structure, the distance of neighboring columns in the axial direction of the tunnel amounts to $7500 \mathrm{~mm}$.

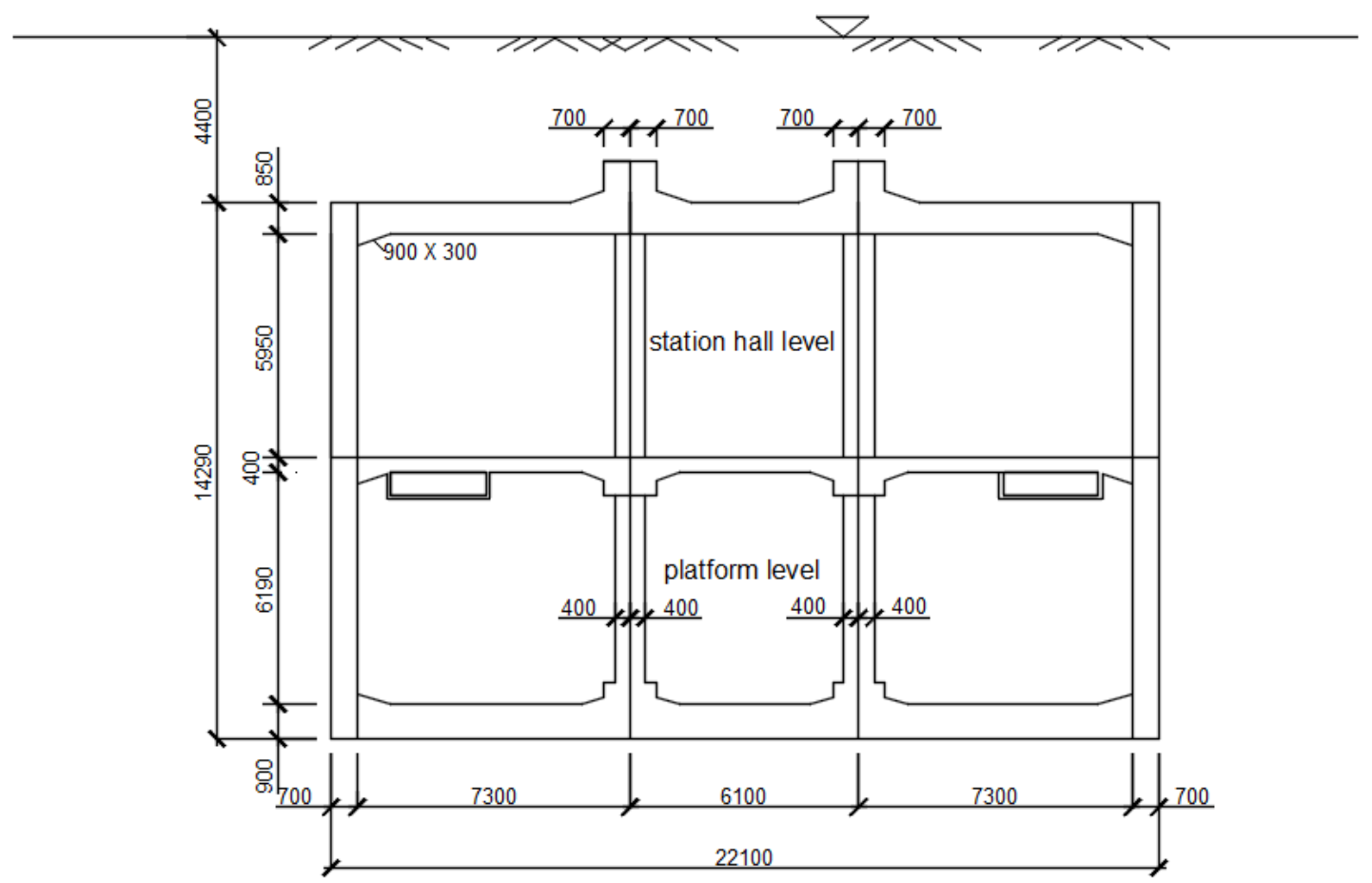

Figure 1. Cross-sectional view (vertical cut through the structure, normal to the axis of the tunnel) of a three-span two-floor reinforced concrete frame, providing the inspiration for fire testing in [40].

\subsection{Production of the Tested Structure}

Inspired by the structure illustrated in Figure 1, a model of the upper floor was tested at a scale of 1:4; see Figure 2 and [40]. The width of the tested structure was $5260 \mathrm{~mm}$; its height was $1880 \mathrm{~mm}$; and its axial length was $1200 \mathrm{~mm}$; see Figure 3. 


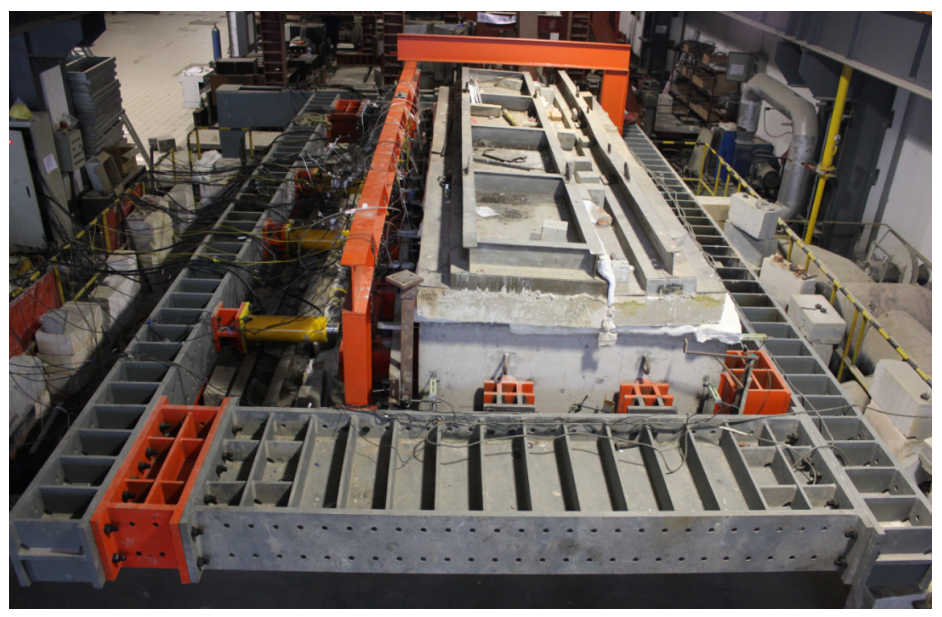

Figure 2. Setup of the large-scale fire test, taken from [40]. The specimen was placed sidelong on top of the furnace and closed with a fire-resistant cover.

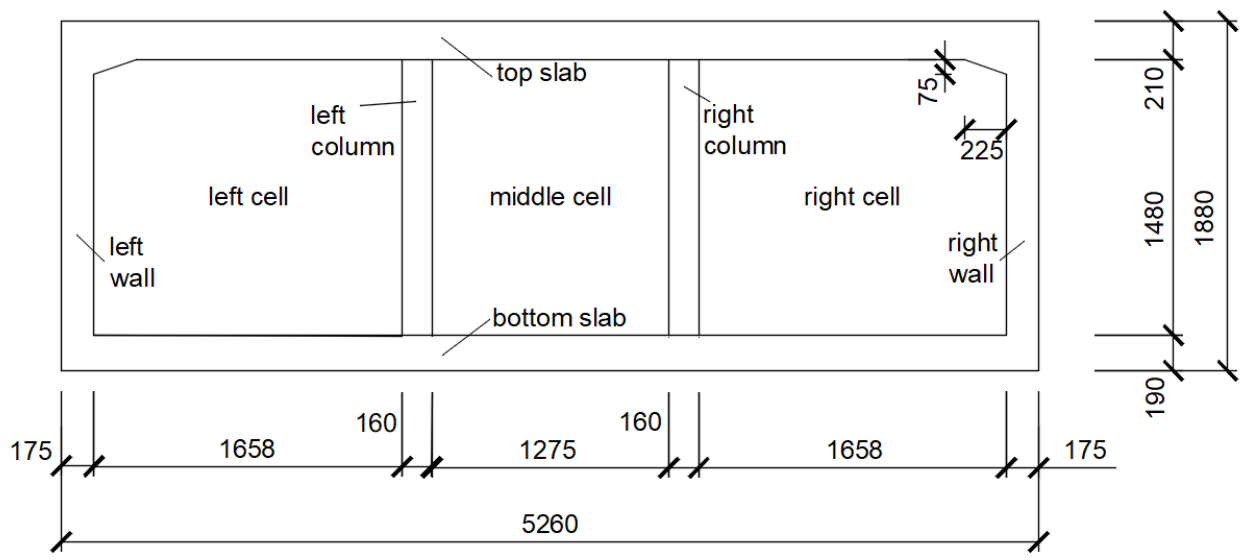

(a)

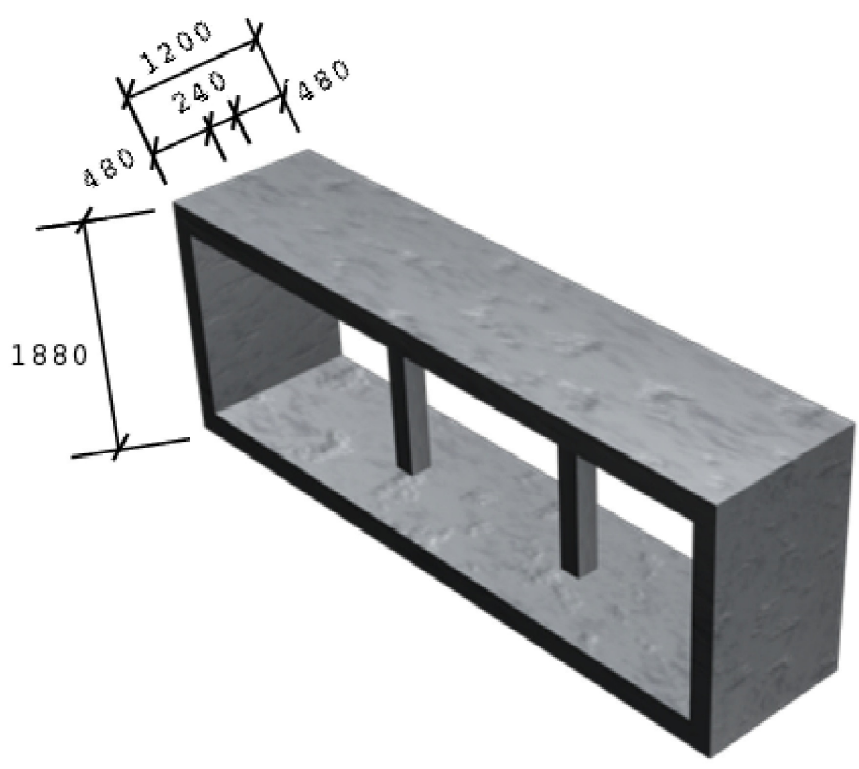

(b)

Figure 3. Geometric dimensions of the tested structure (mm): (a) cross-section and (b) perspective representation; adapted from [40]. 
The dimensions of the top slab and the lateral walls amounted to one fourth of the real dimensions. The total length of the inner span of the structure amounted to $20.7 \mathrm{~m} / 4=5.175 \mathrm{~m}$. However, it had to be slightly adjusted to fit the dimensions of the furnace. Thus, the inner span of the model is $4.91 \mathrm{~m}$, which is equal to that of the furnace. The design of the columns was the result of the following considerations: The scaled distance of neighboring columns in the axial direction of the tunnel amounted to $7.5 \mathrm{~m} / 4=1.875 \mathrm{~m}$. This is by a factor of 1.5652 larger than the axial length of the tested structure. Thus, the 1:4 scaled cross-sectional area of the columns, amounting to $300 \mathrm{~mm} \times 200 \mathrm{~mm}$, had to be divided by a factor of 1.5652; see [40] for details. In order to obtain a geometrically similar cross-section, both scaled dimensions were divided by $\sqrt{1.5652}=1.25$. Therefore, the cross-sectional area of the columns of the tested structure amounted to $240 \mathrm{~mm} \times 160 \mathrm{~mm}$. Finally, the thickness of the bottom slab was set equal to $190 \mathrm{~mm}$, in order to account for the influence of the lower floor on the stiffness of the modeled upper floor; see [40] for details.

The reinforcement ratio of the top slab, the bottom slab, the columns and the walls amounted, by analogy to the real structure, to $1.22 \%, 1.19 \%, 2.95 \%$ and $1.76 \%$, respectively. The reinforcement bars had diameters of $10 \mathrm{~mm}, 12 \mathrm{~mm}$ and $14 \mathrm{~mm}$, respectively; see Figure 4 .

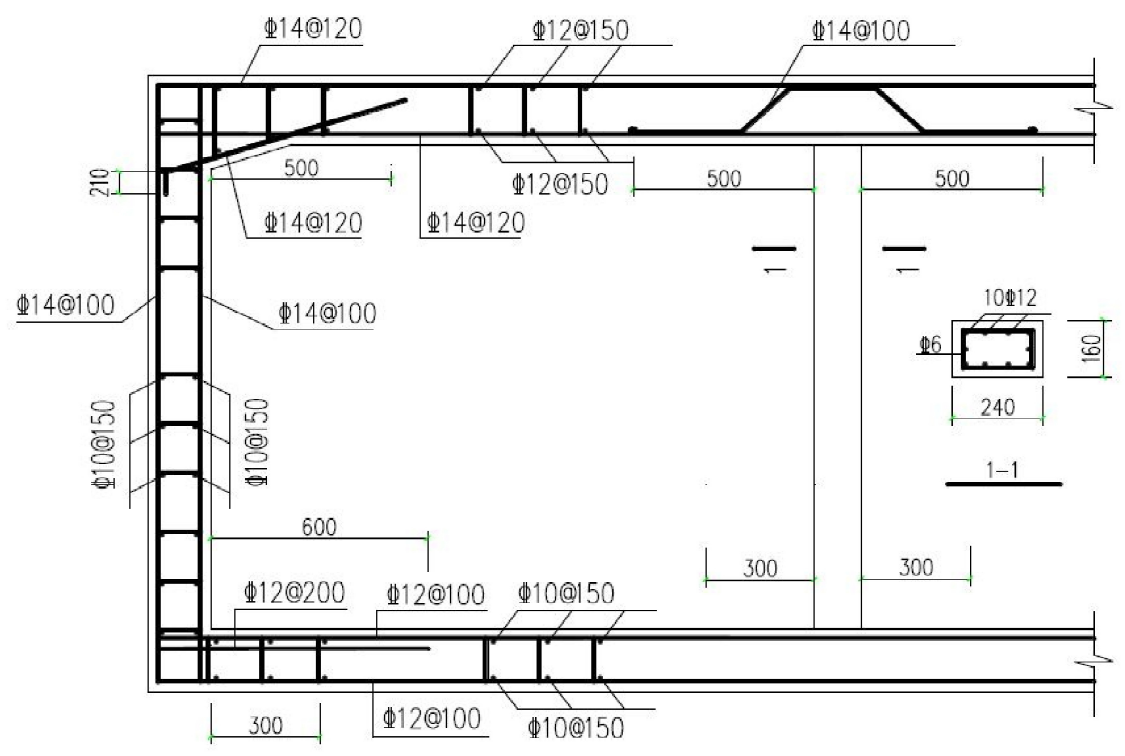

Figure 4. Reinforcement drawing of the tested structure (mm), taken from [40].

Temperature and strain sensors were put in place already before casting of the concrete. In this way, the sensors were finally embedded inside the tested structure. As to be expected in fire testing [45], some of the sensors failed during the experiment. Therefore, the following description is limited to measurement equipment, the readings of which are considered in the present work. Thermocouples were placed at six positions within the tested structure (Figure 5): three in the top slab (one at the midspan of each one of the three cells), one in the right column, one in the right wall and one in the middle cell of the bottom slab. At the selected positions, several sensors were placed at different distances from the heated inner surface, in order to monitor the ingress of heat into the structure; see Figure 5. The minimum cover depth of the thermocouples amounted to $2 \mathrm{~mm}$.

Strain gauges were mounted to steel bars of the inner and the outer reinforcement layer. Measurement positions were located at the top slab, at the midspan of the left cell and at the center of the right wall; see Figure 5.

Normal concrete "C 40 ", with a mass density of $2373 \mathrm{~kg} / \mathrm{m}^{3}$, was used for the production of the tested structure; see Table 1 for the composition of the material. The stiffness and the strength of both concrete and steel were quantified before the test, following protocols from the Chinese Standard for 
Test Method of Mechanical Properties on Ordinary Concrete [46]; see Table 2. Notably, the concrete was tested at an age of 28 days.

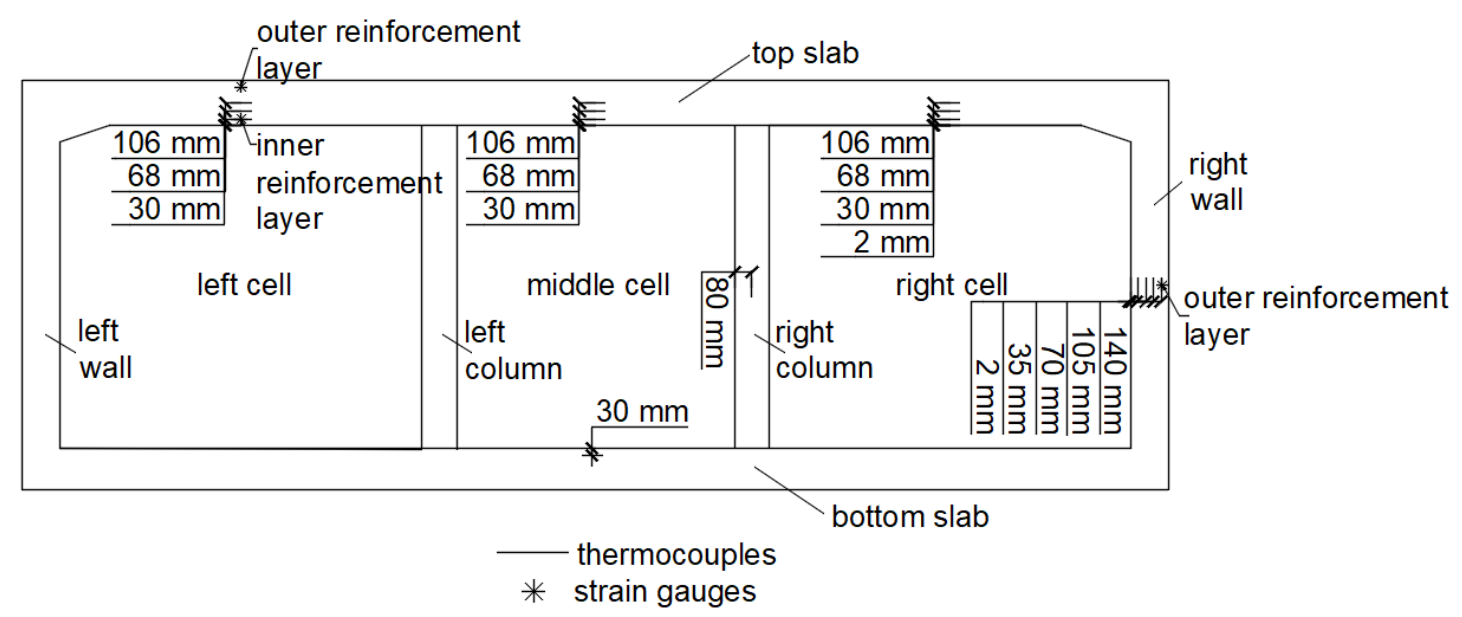

Figure 5. Elements of the tested structure and positions of thermocouples and strain gauges.

Table 1. Composition of the concrete used for the tested structure.

\begin{tabular}{cc}
\hline Raw Material & Content $\mathbf{( k g / \mathbf { m } ^ { 3 } )}$ \\
\hline Cement (42.5 PO) & 249 \\
Tap water & 176 \\
Sand 1 (middle size) & 306 \\
Sand 2 (middle size) & 458 \\
Gravel (5-25 mm) & 1013 \\
Fly ash (Level II) & 70 \\
Admixture (ZK 904-3) & 6 \\
Blast furnace slag S95 & 95 \\
\hline
\end{tabular}

Table 2. Stiffness and strength properties of concrete (age $=28$ days) and steel at room temperature.

\begin{tabular}{ccc}
\hline Material & Compressive Strength (MPa) & Yield Stress (MPa) \\
\hline Concrete & 36.5 & - \\
Steel (diameter $=12 \mathrm{~mm})$ & - & 531.9 \\
Steel (diameter $=14 \mathrm{~mm})$ & - & 530.2 \\
\hline
\end{tabular}

As for the fire experiment, the tested structure was rotated by $90^{\circ}$ and placed in the furnace, such that the axial direction of the modeled tunnel segment was equal to the vertical direction. Additional supports were used to avoid rigid body motions in horizontal planes. Four supports prevented the displacements of the bottom ends of the walls and of the columns; see Figure 6 . As for the displacements in the horizontal direction, orthogonal to the axes of the columns, two supports were positioned at the left wall; see Figure 6. 


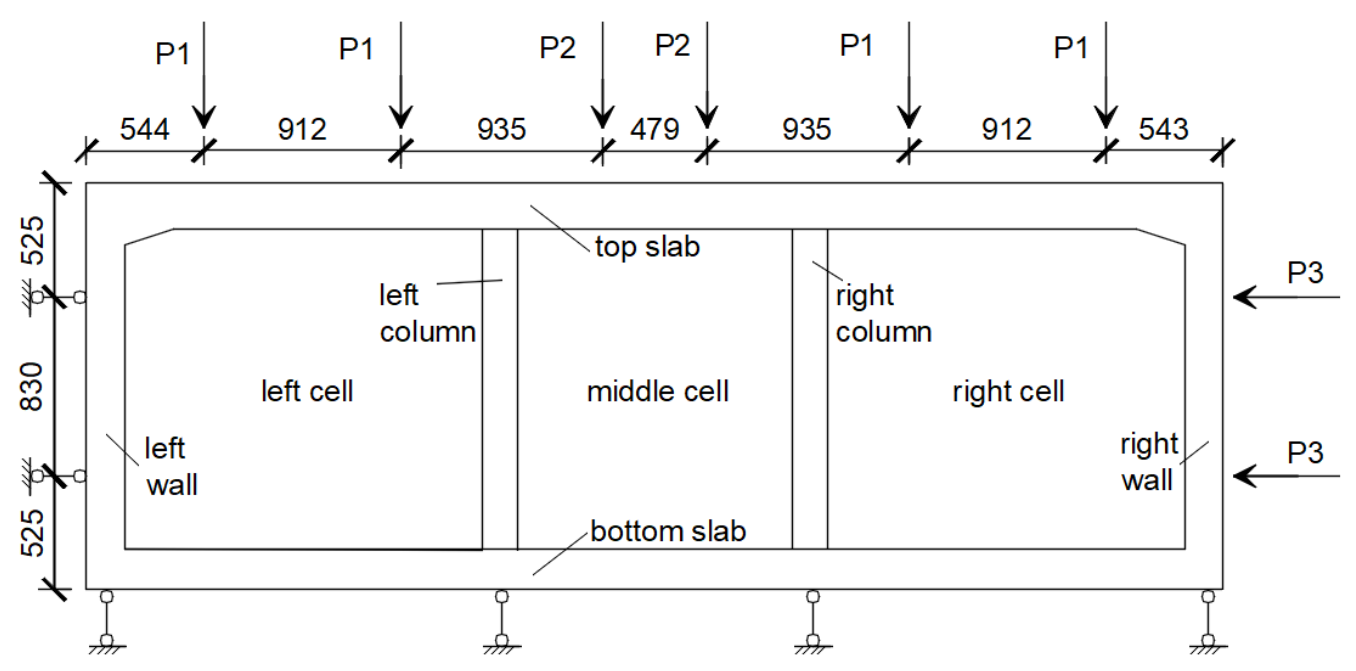

Figure 6. Support and loading conditions of the tested structure, adapted from [40].

\subsection{Mechanical and Thermal Loading}

In order to simulate service conditions, the structure was mechanically loaded in both horizontal directions according to the recommendations by the Chinese Standard for Metro Design [47] and Eurocode 2 [48]. The imposed loads accounted for the effective traffic load at the surface above the real structure $(20 \mathrm{kN} / \mathrm{m})$, the pedestrian load on both stories $(4 \mathrm{kN} / \mathrm{m})$, the earth pressure resulting from a $3.5 \mathrm{~m}$-thick layer of covering soil (specific gravity $=19 \mathrm{kN} / \mathrm{m}^{3}$ ), and the water pressure resulting from a $0.5 \mathrm{~m}$-thick layer of groundwater (specific gravity $=9.8 \mathrm{kN} / \mathrm{m}^{3}$ ). These loads were combined, using safety factors for dead load and live loads, amounting to 1.35 and 1.40 , respectively. The resulting loading scenario was simulated by three sets of concentrated loads, referred to as P1, P2 and P3; see Figure 6 and Table 3. They were applied in nine steps. This took $70 \mathrm{~min}$. Subsequently, the fire test was started.

Table 3. Applied mechanical loads.

\begin{tabular}{cccc}
\hline & P1 & P2 & P3 \\
\hline Load $(k N)$ & 192.0 & 151.2 & 120.0 \\
\hline
\end{tabular}

During the fire test, the temperature of the air inside the cross-section was increased according to a time-dependent temperature history (Figure 7). The latter was the result of a statistical analysis of documented fire accidents. Within $25 \mathrm{~min}$, the temperature was increased to a target value of approximately $525{ }^{\circ} \mathrm{C}$. It was kept constant thereafter. The prescribed fire load accounted for the ventilation of the real structure, with a speed of $2.5 \mathrm{~m} / \mathrm{s}$, automatic sprinkler devices and a heat release rate of $5 \mathrm{MW}$ [40], in accordance with the Chinese Standard for Metro Design [47]. Two controlled heat sources of the furnace were used to produce the thermal loading. The heat was transferred to the tested structure by means of natural (unforced) convection. 


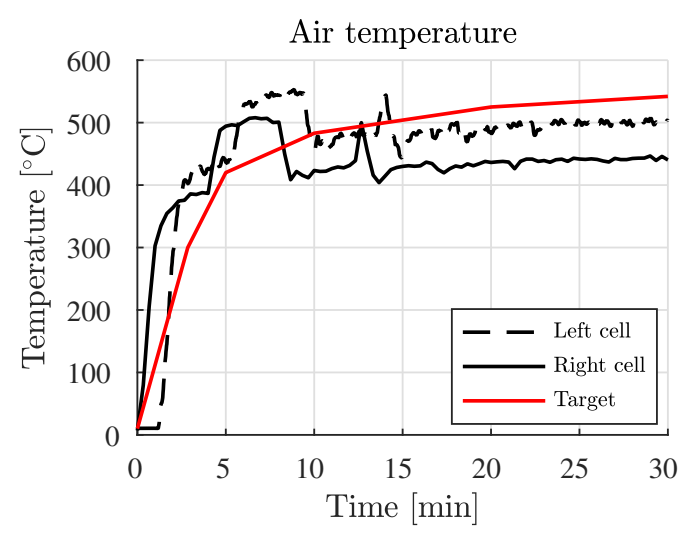

Figure 7. Temperature history of the air inside the tested structure.

\subsection{Results from Structural Monitoring}

The thermocouples and the strain gauges undertook readings every $20 \mathrm{~s}$. Thus, the first $30 \mathrm{~min}$ of the fire test were documented by 90 readings of each sensor.

The temperature close to the inner surface of the top slab, at the midspan of the right cell, rose by approximately $90^{\circ} \mathrm{C}$ during the first $30 \mathrm{~min}$ of the fire test; see Figure $8 \mathrm{a}$. The temperature decreased with increasing distance from the heated inner surface (see the four graphs in Figure 8a), which shows the measured evolutions of temperature changes at distances of $2 \mathrm{~mm}, 30 \mathrm{~mm}, 68 \mathrm{~mm}$ and $106 \mathrm{~mm}$ from the heated inner surface. At a depth equal to or greater than $106 \mathrm{~mm}$, the temperature remained practically constant throughout the analyzed part of the fire test. A qualitatively similar, but quantitatively different behavior was measured at the other measurement positions of the top slab, the right wall and the bottom slab; see Figure 8 d,e. At the center of the right wall, e.g., the temperature close to the inner surface rose by about $80^{\circ} \mathrm{C}$, while no temperature increase was measured at depths equal to or greater than $105 \mathrm{~mm}$. The temperature of the right column was measured at its core, at a distance of $80 \mathrm{~mm}$ to the nearest heated surface. Notably, the core temperature of the column rose significantly more than that at the same depth in the slabs and the right wall. The measured temperature evolution is, in fact, comparable with that at a depth of some $30 \mathrm{~mm}$ in the top slab.

The strain gauges measured deformations resulting from the mechanical loading (see the values labeled as 0-min readings in Figure 9) and the progressive thermomechanical loading (see the evolution of the total strains after 0 min in Figure 9). For instance, at the outer reinforcement layer of the top slab, the strains resulting from the mechanical loading amounted to approximately $-50 \times 10^{-6}$; see the ordinate of the dash-dotted curve at $t=0 \mathrm{~min}$. During the subsequent $30 \mathrm{~min}$ of the fire test, the reading increased by approximately $150 \times 10^{-6}$ to approximately $100 \times 10^{-6}$; see the dashed-dotted graph in Figure 9. This underlines that strains resulting from the thermal loading became the dominant part of the total strains soon after the start of the fire test. Notably, strain changes of the inner rebar resulted from both the eigenstrains, caused by the temperature increase, and the structural load redistributions, induced by the thermal loading. The strain changes of the outer rebar, where the temperature remained constant throughout the analyzed part of the fire test, resulted exclusively from redistribution of the structural load. 


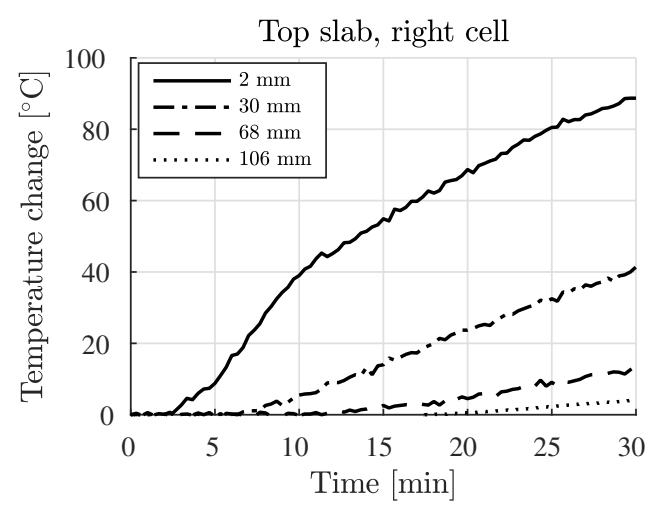

(a)

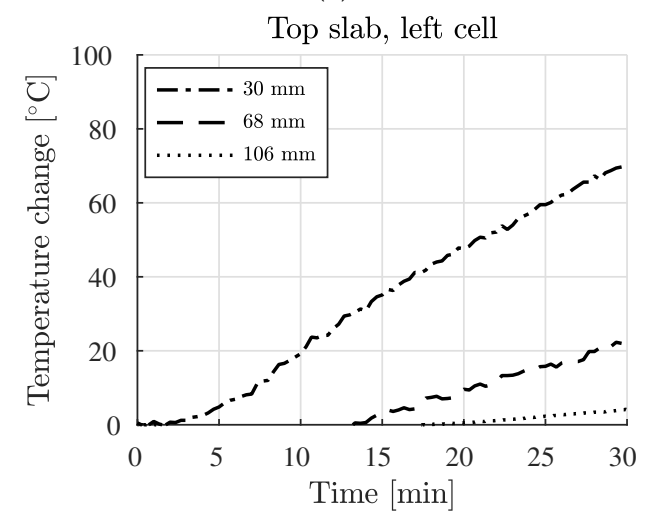

(c)

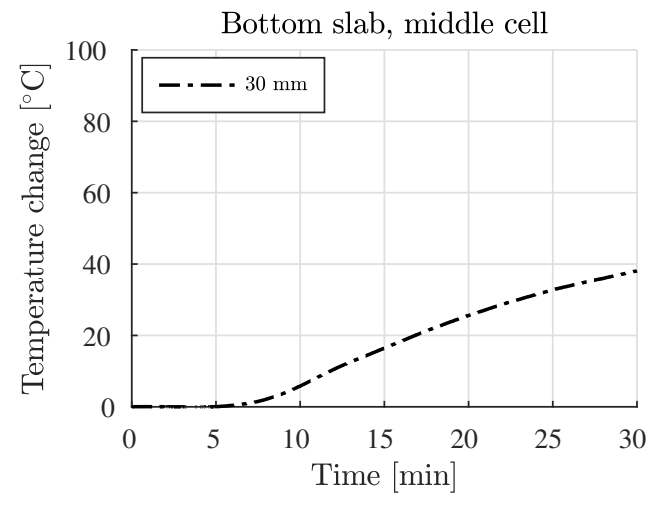

(e)

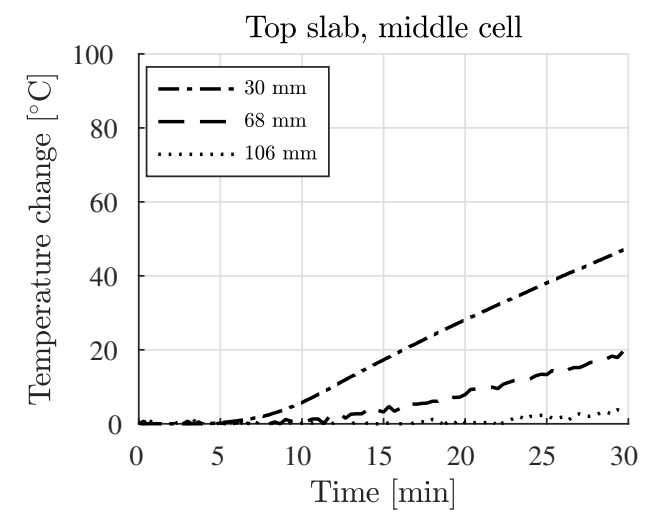

(b)

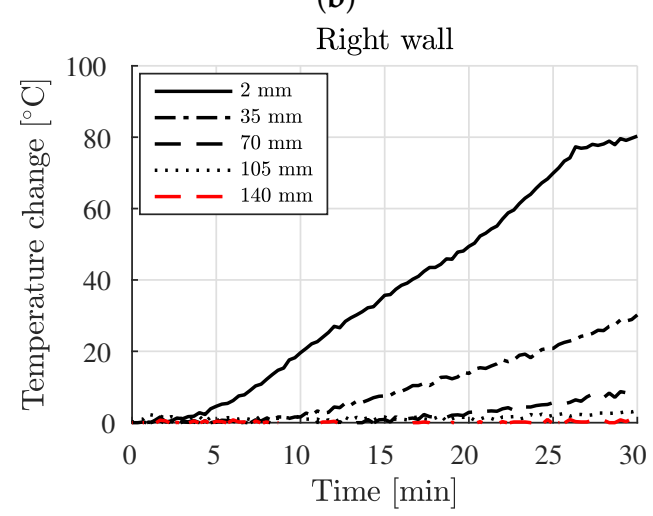

(d)

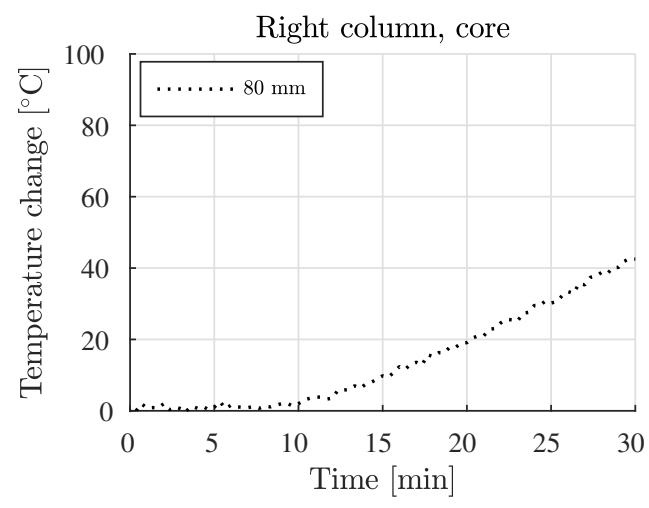

(f)

Figure 8. Measured evolutions of temperature changes: (a) top slab, at the midspan of the right cell, (b) top slab, at the midspan of the middle cell, (c) top slab, at the midspan of the left cell, (d) center of the right wall, (e) bottom slab, at the midspan of the middle cell, and (f) core of the right column. 


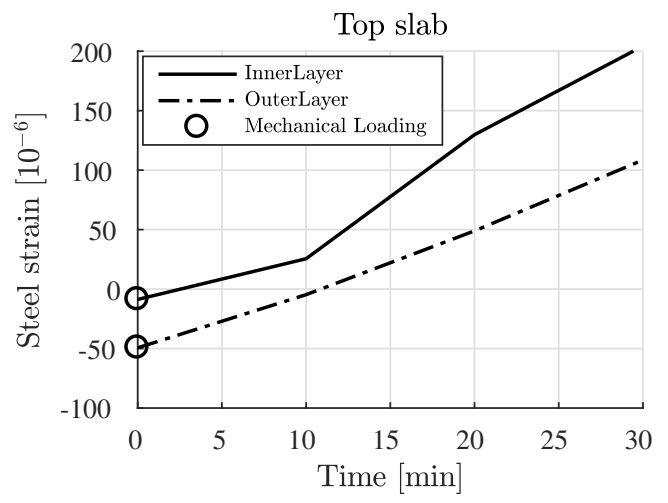

(a)

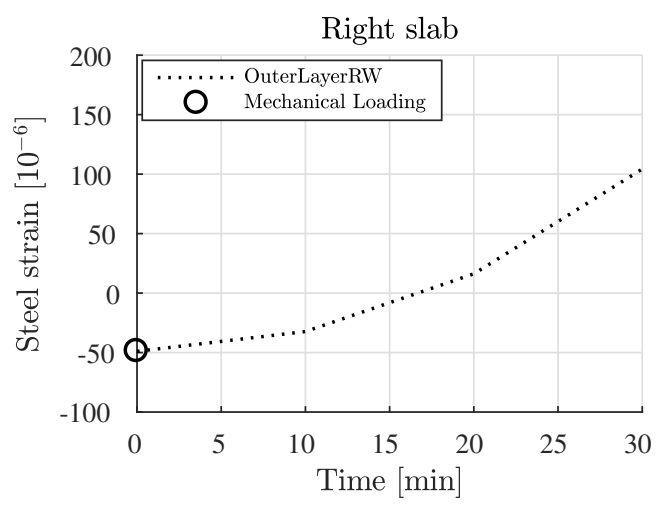

(b)

Figure 9. Measured evolutions of total strains of steel rebar: (a) top slab, at the midspan of the left cell, and (b) center of the right wall.

\section{Transient Simulation of Non-Stationary Heat Conduction}

Heat conduction within the tested structure was simulated by means of three-dimensional non-stationary Finite Element simulations using the commercial software Abaqus FEA 2016. The Finite Element mesh (Figure 10) was the result of a convergence study. It was a satisfactory trade-off between simulation accuracy and computational effort [49]. The mesh consisted of 139,040 linear hexahedral brick finite elements, with eight nodes and one temperature degree of freedom per node. These elements are referred to as "DC3D8" by Abaqus [42]. The characteristic size of the finite elements amounted to $3 \mathrm{~cm}$. Notably, there are studies $[23,50]$ showing that the steel bars have an insignificant influence on the heat conduction problem. For this reason, the thermal properties of concrete were assigned to all finite elements for the simulation of the non-stationary heat conduction problem. This analysis was only made for the analysis of heat conduction. For the subsequent thermomechanical analysis, the specific properties of concrete and steel were assigned to the corresponding elements.

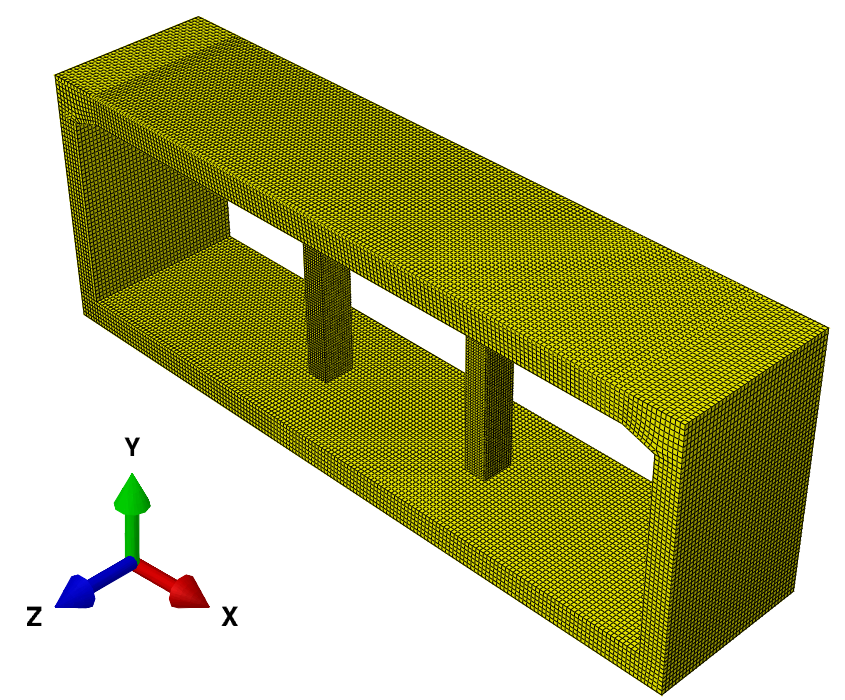

Figure 10. Three-dimensional Finite Element mesh of the analyzed structure and the Cartesian coordinate system used.

The thermal properties of the concrete of the tested structure were unknown. As a remedy, the values of the specific heat capacity and the thermal conductivity were estimated in accordance with building codes $[43,44,51,52]$ and scientific studies [53-55]; see Table 4. These values refer to room temperature. Notably, the experimental measurements suggest that the temperature of the structure remained below $100{ }^{\circ} \mathrm{C}$ during the first $30 \mathrm{~min}$ of the fire test (see Figure 8 ) and, thus, that the 
evaporable water of the concrete was not released [53,56]. This served as a motivation to assume, in the spirit of a reductionist approach, that the thermal properties of concrete at room temperature are a reasonable approximation throughout the entire analysis, although the thermal conductivity of concrete decreases to some $90 \%$ of its room-temperature value, provided that the material is heated up to $100^{\circ} \mathrm{C}$; see the building codes $[43,44,52]$ and the scientific studies $[1,53,55,57,58]$.

Table 4. Thermal properties of concrete at room temperature.

\begin{tabular}{lc}
\hline Property & Value \\
\hline Specific heat capacity $(\mathrm{J} /(\mathrm{kgK}))$ & 900 \\
Thermal conductivity $(\mathrm{W} /(\mathrm{mK}))$ & 1.6 \\
\hline
\end{tabular}

As regards the boundary conditions, the simulations were based on histories of temperature fields that were prescribed at the inner and outer surfaces of the simulated structure. This approach was appealing as it rendered a computational fluid dynamics simulation of heat transfer from the hot air to the simulated structure dispensable. Such simulations are rather challenging, because of thermal instabilities occurring inside the highly turbulent air flow $[34,59,60]$. Herein, the temperature at the outer surface of the simulated structure was set equal to the initial temperature, $T_{i n i}=10^{\circ} \mathrm{C}$, throughout the entire simulation. This agrees with the experimental measurements. As for the time-dependent temperature field prescribed at the heated inner surface, two different strategies were implemented within the framework of a sensitivity analysis: (i) spatially-uniform heating of the entire inner surface of the structure and (ii) piecewise spatially-uniform heating of three sub-regions of the inner surface.

\subsection{Uniform Prescription of One Temperature History}

At the entire inner surface of the simulated structure, the same temperature history was prescribed; see the blue dotted graphs, labeled "BC", in Figure 11. The prescribed evolution of the surface temperature was obtained by averaging the readings of the two thermocouples that were positioned at a distance of $2 \mathrm{~mm}$ from the heated inner surface; see the dotted black lines in Figure 11a,d. The other graphs shown in Figure 11a refer to the simulated (label "Sim") or measured (label "Meas") evolutions of temperature changes at positions $30 \mathrm{~mm}, 68 \mathrm{~mm}$ and $105 \mathrm{~mm}$ away from the heated inner surface; see also Figure 5.

The results of the numerical simulations (Figures 12 and 13) overestimated the experimentally measured temperatures at the right wall, while underestimations were obtained at all other positions that were equipped with thermocouples; see Figure 11. The largest percent underestimation, obtained $30 \mathrm{~min}$ after the start of the fire test, amounted to some $70 \%$ and referred to the temperature evolution of the column; see Figure 11f. This was the motivation to refine the numerical simulations by means of updating of the model.

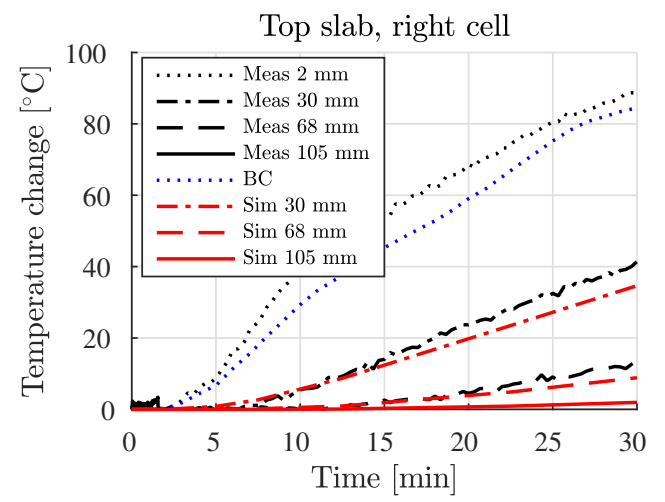

(a)

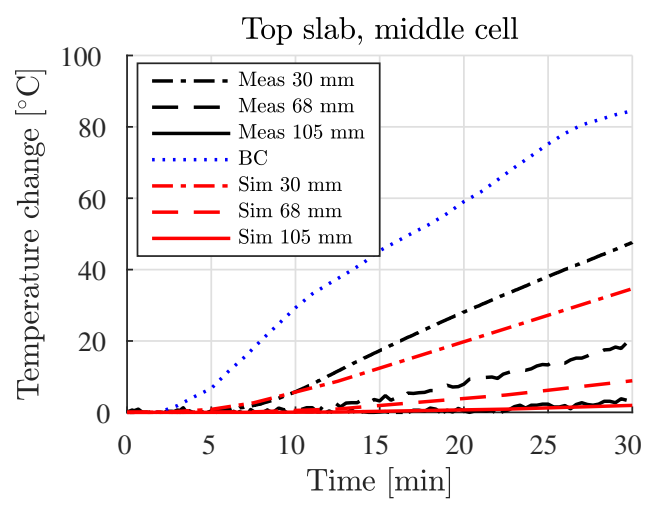

(b)

Figure 11. Cont. 


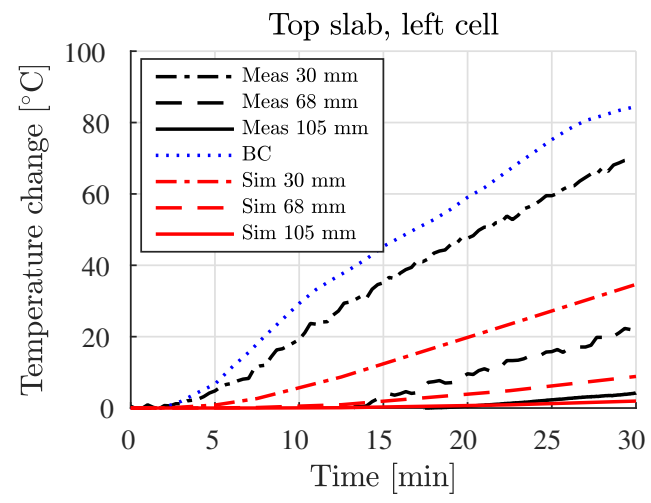

(c)

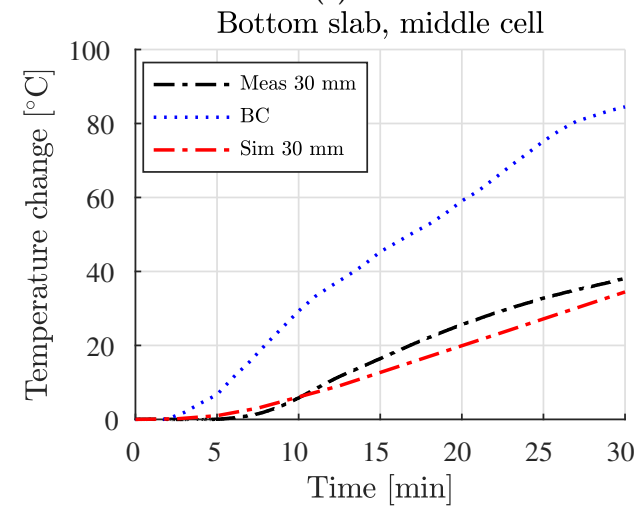

(e)

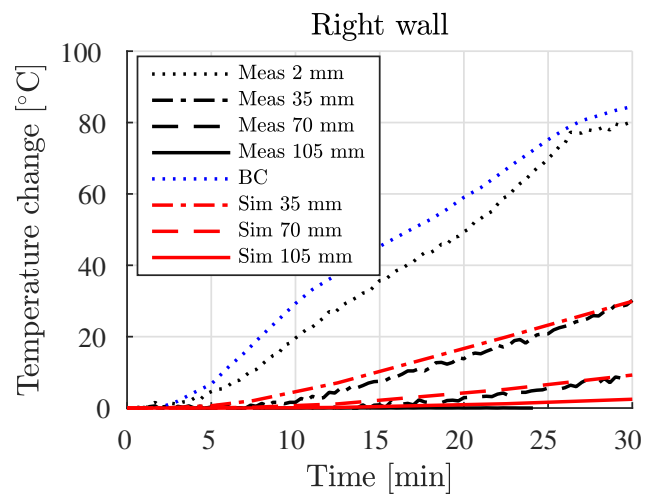

(d)

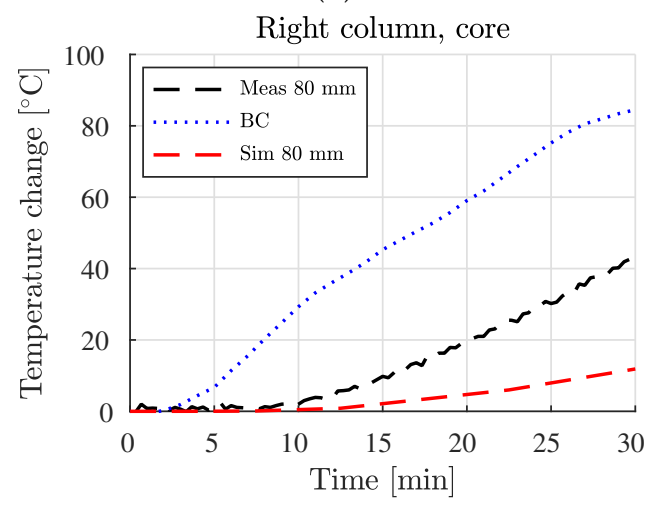

(f)

Figure 11. Comparison of simulated evolutions of the temperature inside the analyzed structure, obtained by prescribing a spatially-uniform temperature history along the entire inner surface, with experimental data: (a) top slab, at the midspan of the right cell, (b) top slab, at the midspan of the middle cell, (c) top slab, at the midspan of the left cell, (d) center of the right wall (e) bottom slab, at the midspan of the middle cell, and (f) core of the right column. Sim, simulated; Meas, measured.

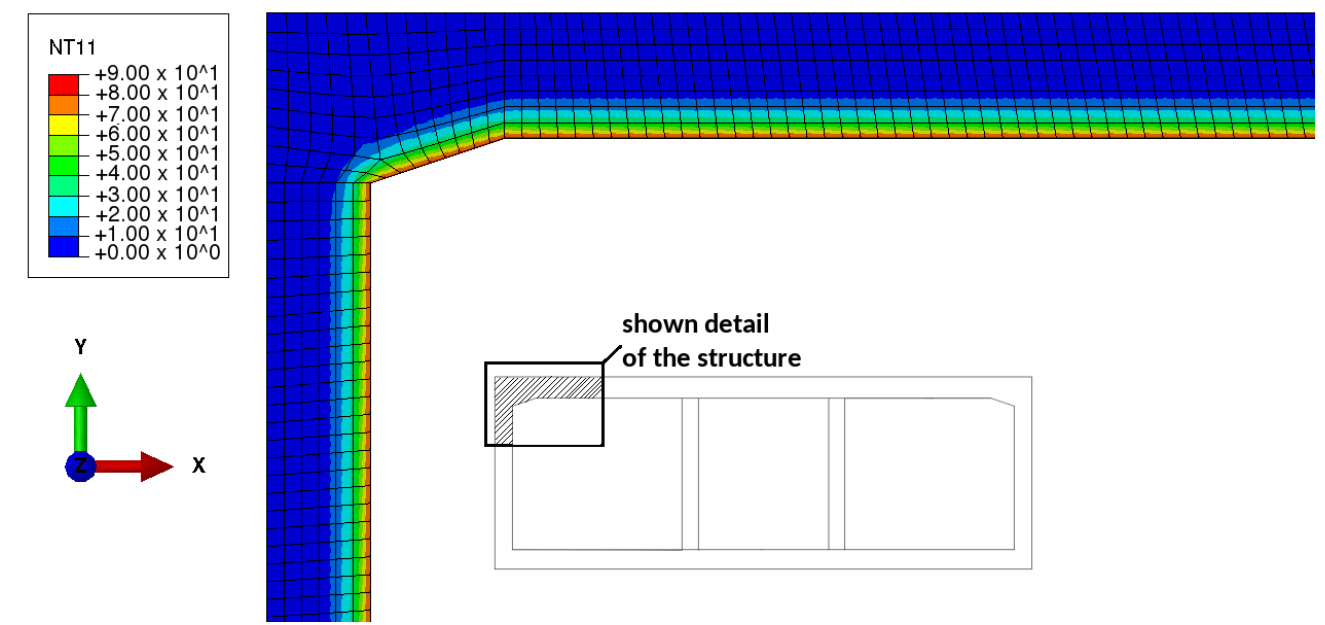

Figure 12. Temperature distribution obtained by prescribing a uniform surface temperature history, 30 min after the start of the thermal loading: detail showing the connection of the left wall to the top slab. 

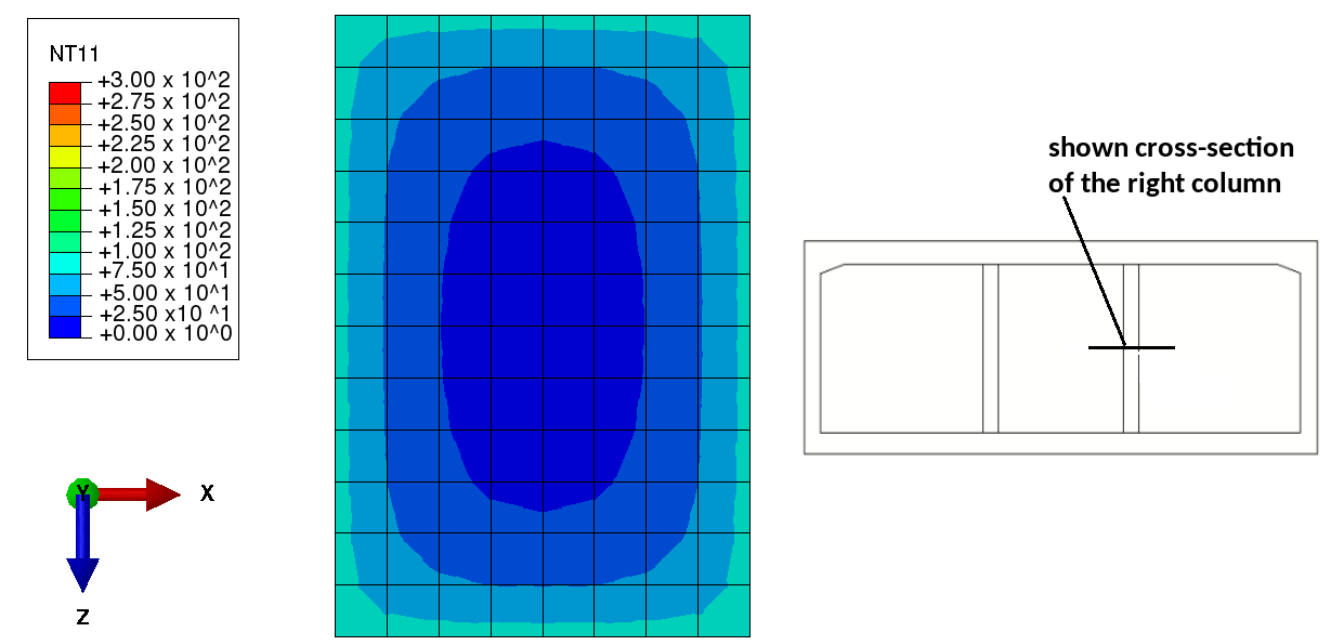

Figure 13. Temperature distribution obtained by prescribing a uniform surface temperature history, $30 \mathrm{~min}$ after the start of the thermal loading: detail showing the central cross-section of the right column.

\subsection{Piecewise Uniform Prescription of Three Specific Temperature Histories}

The results of the preceding section suggested that the right column was exposed to higher surface temperatures compared to the near-surface-measurements at the top slab and the right wall. In order to improve the agreement between simulation results and experimental measurements, the inner surface of the analyzed structure was subdivided into three sub-regions. In each of them, a specific temperature history was prescribed at the inner surface in a spatially-uniform fashion. This was done such that the symmetry of the simulated heat conduction problem was preserved.

1. The top and bottom slabs were subjected to the temperature history, measured at the midspan of the left cell of the top slab, at a depth of $2 \mathrm{~mm}$ from the heated surface.

2. Both walls were subjected to the temperature history, measured at the center of the right wall, at a depth of $2 \mathrm{~mm}$ from the heated surface.

3. Both columns were subjected to the temperature history imposed on the top and bottom slabs, amplified by a fitting-factor. This was done, noting that the temperature was not measured near the surface of the columns and that, because of their position and their larger exposed-surface-to-volume ratio, the columns were expected to heat up faster than the slabs and the walls. This was confirmed by the results from the previous section. Furthermore, since the same source that heated the slabs also heated the columns, similar qualitative temperature evolutions were assumed to occur at both positions. Setting the amplifying factor equal to 3.2 provided satisfactory agreement between the simulated and the measured temperature evolutions.

The three different prescribed temperature histories are shown as blue dotted graphs, labeled "BC", in Figure 14.

The simulated and measured temperatures agree well at the positions where near-surfacemeasurements are available, provided that the temperature history measured at a depth of $2 \mathrm{~mm}$ is prescribed as the boundary condition at the surface; see Figure 14a,d. At these positions, the maximum difference between the simulated and the measured temperatures amounts to $3.6^{\circ} \mathrm{C}$ and $1.4{ }^{\circ} \mathrm{C}$, respectively. This underlines the fact that the heat transfer was predominantly one-dimensional at these positions and took place in the direction orthogonal to the heated surface.

The simulated and measured temperatures also agree well at the middle cell of the bottom slab. Here, the maximum difference between the simulated and the measured temperatures is $2.5^{\circ} \mathrm{C}$. This suggests that the two surfaces at the midspan positions of the right cell of the top slab and of the middle cell of the bottom slab were exposed to very similar temperature histories; see Figure 14a,e.

The updated simulation (Figure 15) suggests that the temperature increase at the surface of the right column was significantly larger than the available near-surface-measurements at the top slab and 
the right wall. In the updated simulation, the maximum surface temperature of the columns amounts to $284^{\circ} \mathrm{C}$, and the difference between the simulated and the measured temperatures amounts to $3.1^{\circ} \mathrm{C}$. In this context, it is emphasized that the updated simulation was simply based on constant thermal properties of concrete (Table 4).

As for the top slab, at the midspan positions both in the middle and the left cell, also the updated simulation does not deliver satisfactory results; see Figure 14b,c. This underlines the fact that the thermal loading of the top slab was characterized by significant gradients of the surface temperature across the three cells.

Good agreement between simulated and measured temperatures would likely be achieved by amplifying, separately for the middle and the left cell, the history of the surface temperature that was so far prescribed. The corresponding subdivision of the heated surface of the simulated structure into five sub-regions, with a specific temperature history for each of them, could be the target of another refinement step. Still, temperature measurements remain unavailable for the right and the left cell of the bottom slab, the left wall and the left column. Thus, the re-analysis of the fire test inevitably requires assumptions concerning the specific histories of the surface temperature in these regions. Alternatively, one could fit them such that the subsequent thermomechanical simulations deliver strains that agree well with the available strain measurements. This would result in the best-possible reproduction of the available experimental data. However, the involved fitting process would render the assessment of the sensitivity of simulation results with respect to the simulated material behavior of concrete very difficult. Since this sensitivity is a central focus of the present contribution, it was decided to stay with the two described strategies of prescribing thermal boundary conditions along the heated inner surface of the analyzed structure and to combine them with two strategies of accounting for the material behavior of concrete. A discussion of the simulation results in the regions of the structure that were not equipped with thermocouples is given in Appendix A.

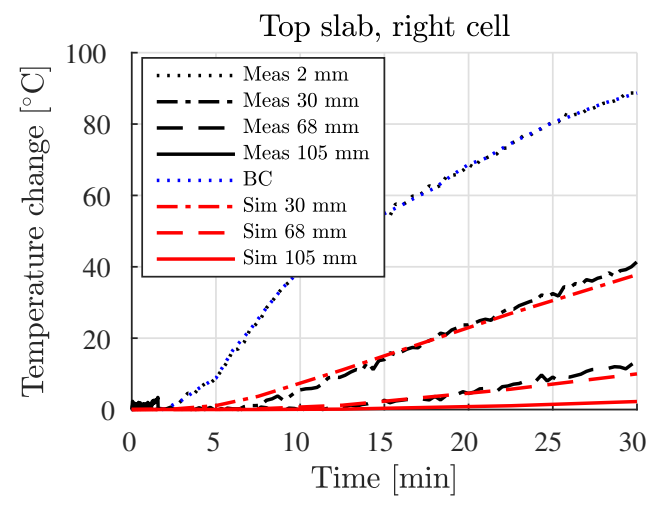

(a)

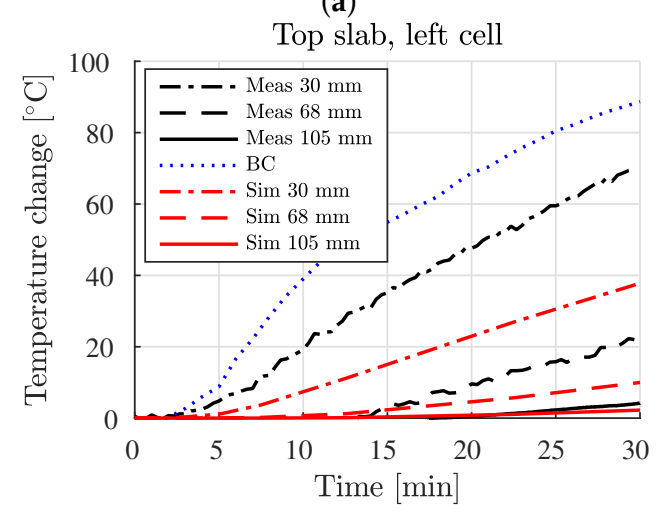

(c)

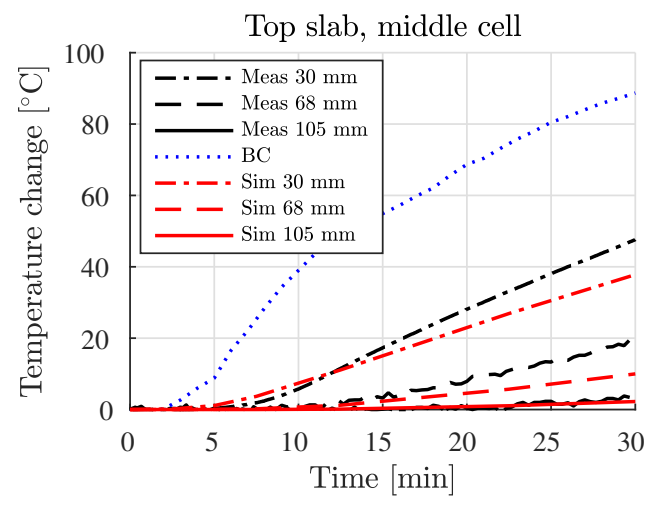

(b)

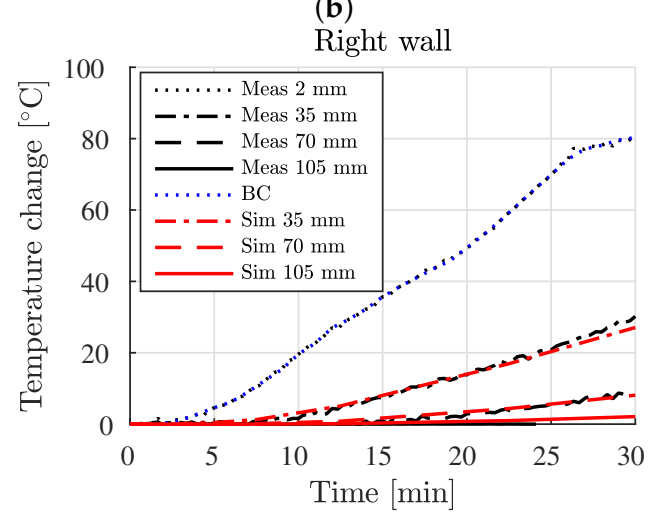

(d)

Figure 14. Cont. 


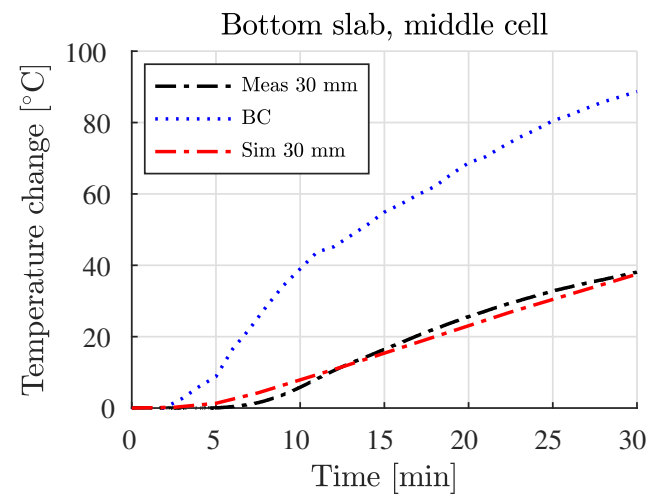

(e)

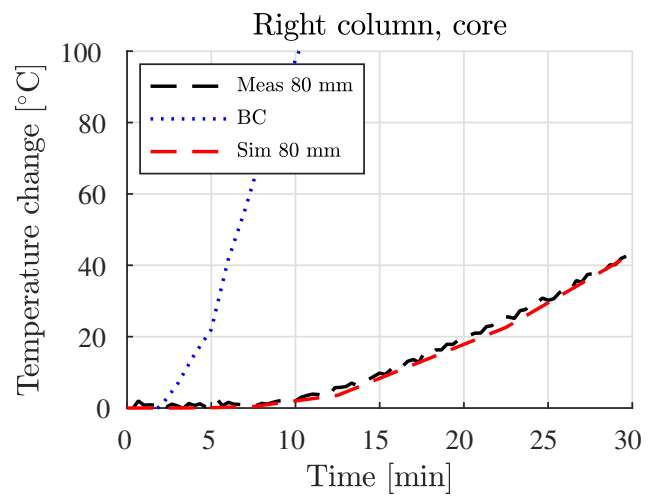

(f)

Figure 14. Comparison of the simulated evolutions of the temperature inside the analyzed structure, obtained by prescribing three piecewise spatially-uniform temperature histories along the inner surface, with experimental data: (a) top slab, at the midspan of the middle cell, (b) top slab, at the midspan of the right cell, (c) top slab, at the midspan of the left cell, (d) center of the right wall (e) bottom slab, at the midspan of the middle cell, and (f) core of the right column.
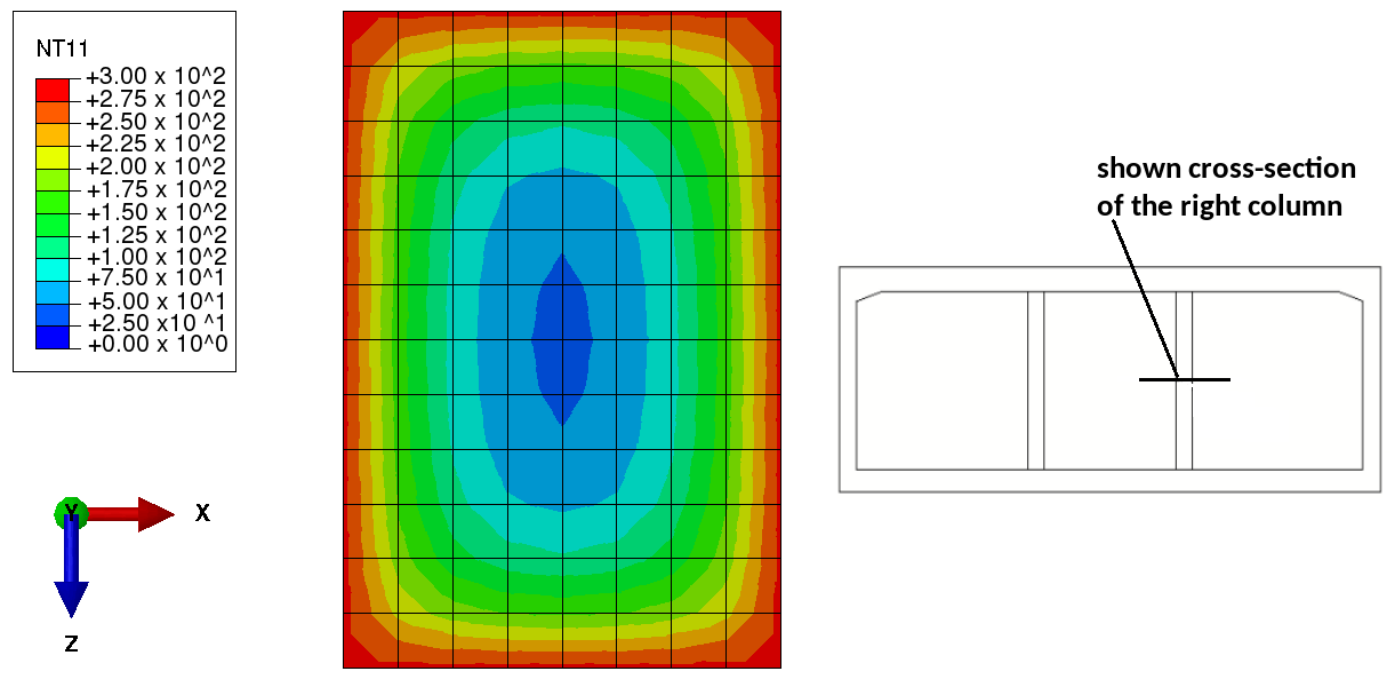

Figure 15. Temperature distribution obtained by prescribing three piecewise uniform surface temperature histories, $30 \mathrm{~min}$ after the start of the thermal loading: detail showing the central cross-section of the right column.

\section{Thermomechanical Simulation at Selected Time Instants}

The load-carrying behavior of the tested structure was analyzed by means of three-dimensional Finite Element simulations, using Abaqus FEA 2016. The chosen Finite Element mesh was similar to the one used for the thermal simulations; see Figure 10. The concrete structure was modeled by 139,040 hexahedral elements of type "C3D8R", i.e., eight-node linear elements with reduced integration and hourglass control, with three translational degrees of freedom per node. The steel rebar was considered by 18,035 line elements of type "T3D2", i.e., two-node linear three-dimensional truss elements, with an axial displacement degree of freedom per node. Perfect bond between concrete and steel rebar was assumed by attaching the nodes of the steel elements to the nodes of the concrete elements.

The supports of the structure were accounted for by means of prescribing displacement boundary conditions. Four sets of such boundary conditions were prescribed in order to prevent displacements of the bottom ends of the walls and of the columns, in the direction of the axes of the columns; see Figure 6. Two additional sets of displacement boundary conditions were prescribed in order to 
prevent horizontal displacements of the left wall, in the direction orthogonal to the axes of the columns; see Figure 6.

The external mechanical loads, imposed on the structure, were accounted for by means of prescribing traction boundary conditions. The six concentrated forces, acting on the top slab, and two loads, acting on the right wall (Figure 6), were prescribed by means of equivalent pressures amounting to $13.3 \mathrm{MPa}$.

The thermomechanical simulation was organized by analogy to the sequence of actions during the analysis of the experiment. At first, the external forces were applied. While they were kept constant thereafter, the temperature fields, computed in Section 3, were prescribed as a time-dependent input, resulting in a transient thermomechanical loading of the structure.

Combined sensitivity analyses were carried out, in order to study the sensitivity of simulation results with respect to uncertainties regarding the thermal loading and the material behavior of concrete. As for the first type of sensitivity analysis, the two different temperature field histories, computed in Section 3, were imposed on the structure, by way of two different simulations. As for the second type of sensitivity analysis, two different types of material models were used for the simulation of concrete. It was either modeled as a linear-elastic material with temperature-independent material properties or as an elasto-plastic material with temperature-dependent material properties, as described in the following.

\subsection{Material Behavior of Concrete and Steel}

\subsubsection{Thermoelastic Properties at Room Temperature}

The expected value of Young's modulus of concrete, $E_{c}$, was estimated based on the mean value of the experimentally-determined values of the compressive strength, $f_{c, p}=36.5 \mathrm{MPa}$; see Table 2 . Notably, these strength values were obtained by crushing prismatic specimens with the following dimensions: $150 \mathrm{~mm} \times 150 \mathrm{~mm} \times 300 \mathrm{~mm}$. The corresponding mean value of the cube compressive strength (referring to specimens with dimensions $150 \mathrm{~mm} \times 150 \mathrm{~mm} \times 150 \mathrm{~mm}$ ), $f_{c, c u}$, was estimated, based on the following regulation of the Chinese Practice Manual for Design of Concrete Structures [61],

$$
f_{c, c u}=\frac{f_{c, p}}{\alpha_{1} \alpha_{2}}=48.03 \mathrm{MPa},
$$

where $\alpha_{1}=0.76$ and $\alpha_{2}=1$ for the investigated concrete.

The corresponding mean value of the cylinder strength, $f_{c, c y}$, was estimated, following Eurocode 2 [48]:

$$
f_{c, c y}=\frac{f_{c, c u}}{1.2}=40.03 \mathrm{MPa} .
$$

The sought value of $E_{c}$ follows from [48] as:

$$
E_{c}=22 \mathrm{GPa} \times\left(\frac{f_{c, c y}}{10 \mathrm{MPa}}\right)^{0.3}=33.35 \mathrm{GPa} .
$$

Poisson's ratio of the concrete was set equal to 0.2 , and the coefficient of thermal expansion of concrete was chosen as $9.03 \times 10^{-6} /{ }^{\circ} \mathrm{C}$; see also Table 5 . This value was obtained as follows: The Eurocode [43] provides formulae for the thermal strain as a function of the temperature for different types of concrete. The considered thermal expansion coefficient refers to concrete made of siliceous aggregates, and it was computed as the slope of the described function, evaluated at room temperature $T_{\text {room }}=20^{\circ} \mathrm{C}$.

The values of the thermomechanical properties of steel were taken from [40]. Young's modulus, Poisson's ratio and the coefficient of thermal expansion amount to $195 \mathrm{GPa}, 0.3$ and $12.2 \times 10^{-6} /{ }^{\circ} \mathrm{C}$, respectively; see Table 5 . 
Table 5. Mechanical properties of concrete and steel at room temperature.

\begin{tabular}{lcc}
\hline Property & Concrete & Steel \\
\hline Young's modulus $(\mathrm{GPa})$ & 33.4 & 195 \\
Poisson's ratio $(-)$ & 0.2 & 0.3 \\
Thermal expansion coefficient $\left({ }^{\circ} \mathrm{C}^{-1}\right)$ & $9.03 \times 10^{-6}$ & $12.2 \times 10^{-6}$ \\
\hline
\end{tabular}

\subsubsection{Evolution of Thermoelastic Properties resulting from Thermal Loading}

The evolution of the elastic stiffness, the strength and the coefficient of thermal expansion of both concrete and steel, resulting from thermal loading up to $300{ }^{\circ} \mathrm{C}$, are discussed, based on regulations of the Eurocode [43], recommendations of the fib Model Code 2010 [44] and the results from scientific studies [53]. This was motivated by results from the thermal simulation with piecewise spatially-uniform histories of surface temperatures, which suggests that the maximum temperature of the columns rose up to $280^{\circ} \mathrm{C}$; see Figure $14 \mathrm{f}$. As regards the thermal degradation of Young's modulus of concrete and steel, scientific results from Bažant et al. [53] and regulations of the Eurocode [43] were used. The reductions of Young's modulus of concrete and steel are expressed relative to their reference values at room temperature; see the first two columns of Tables 6 and 7, respectively. Linear interpolation was used to quantify these moduli between the listed values. Poisson's ratio of concrete and steel were assumed to be temperature-independent. Thus, they are set equal to the values listed in Table 5.

Table 6. Temperature-dependent thermoelastic properties of concrete.

\begin{tabular}{cccc}
\hline $\begin{array}{c}\text { Temperature } \\
\boldsymbol{T}\left({ }^{\circ} \mathbf{C}\right)\end{array}$ & $\begin{array}{c}\text { Young's Modulus } \\
E_{c}(T) / E_{c}\left(T_{\text {room }}\right)(-)\end{array}$ & $\begin{array}{c}\text { Compressive Strength } \\
f_{c}(T) / f_{c}\left(T_{\text {room }}\right)(-)\end{array}$ & $\begin{array}{c}\text { Coefficient of Thermal } \\
\text { Expansion } \alpha_{T}\left({ }^{\circ} \mathbf{C}^{-1}\right)\end{array}$ \\
\hline 20 & 1.00 & 1.00 & $9.03 \times 10^{-6}$ \\
100 & 0.85 & 1.00 & $9.70 \times 10^{-6}$ \\
200 & 0.72 & 0.95 & $11.7 \times 10^{-6}$ \\
300 & 0.60 & 0.85 & $15.2 \times 10^{-6}$ \\
\hline
\end{tabular}

Table 7. Temperature-dependent thermoelastic properties of steel.

\begin{tabular}{cccc}
\hline $\begin{array}{c}\text { Temperature } \\
\boldsymbol{T}\left({ }^{\circ} \mathrm{C}\right)\end{array}$ & $\begin{array}{c}\text { Young's Modulus } \\
\boldsymbol{E}_{\boldsymbol{S}}(T) / \boldsymbol{E}_{\boldsymbol{s}}\left(T_{\text {room }}\right)(-)\end{array}$ & $\begin{array}{c}\text { Yield Stress } \\
f_{y}(T) / f_{y}\left(T_{\text {room }}\right)(-)\end{array}$ & $\begin{array}{c}\text { Coefficient of Thermal } \\
\text { Expansion } \alpha_{T}\left({ }^{\circ} \mathbf{C}^{-\mathbf{1}}\right)\end{array}$ \\
\hline 20 & 1.00 & 1.00 & $12.2 \times 10^{-6}$ \\
100 & 1.00 & 1.00 & $12.8 \times 10^{-6}$ \\
200 & 0.90 & 1.00 & $13.6 \times 10^{-6}$ \\
300 & 0.80 & 1.00 & $14.4 \times 10^{-6}$ \\
\hline
\end{tabular}

As for the thermal degradation of the uniaxial compressive strength of concrete and the yield stress of hot rolled steel, regulations of the Eurocode [43] were used. The reduction of the compressive strength of concrete relative to its reference values at room temperature is listed in the first and the third columns of Table 6. Linear interpolation was used to quantify the compressive strength between the listed values.

The temperature-dependent coefficients of thermal expansion of both concrete and steel were chosen according to the regulations of the Eurocode 2 [43]; see Tables 6 and 7 for specific values at characteristic temperatures. The continuous representations of the underlying nonlinear evolutions are illustrated in Figure 16. 


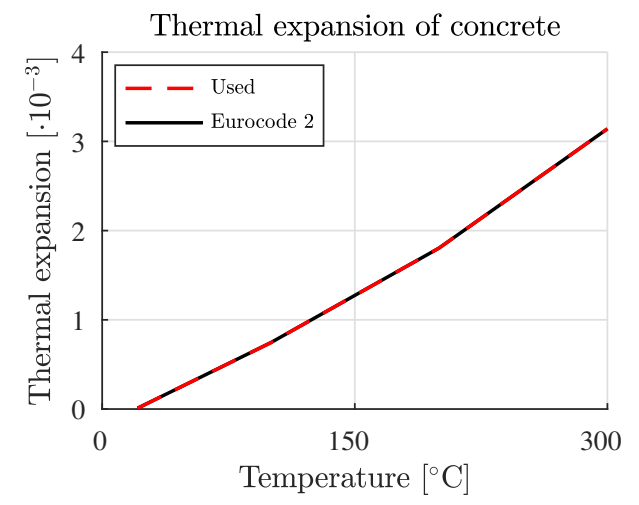

(a)

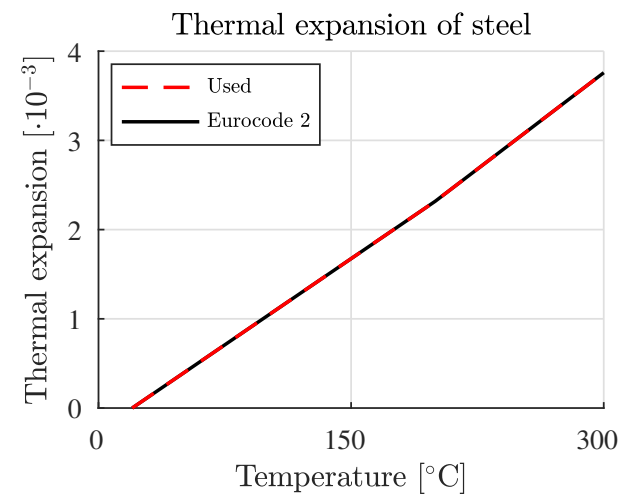

(b)

Figure 16. Coefficients of thermal expansion as a function of the temperature, according to Eurocode 2 [43], for: (a) concrete and (b) steel.

\subsubsection{Constitutive Behavior: Elasto-Plastic Material Models for Concrete and Steel}

The multiaxial elasto-plastic constitutive behavior of concrete was accounted for by means of the "Concrete Damaged Plasticity" model of Abaqus [42]; see Appendix B for more information regarding the model and the specific input parameters. As for uniaxial compression, stress-strain relations based on the regulations of the Eurocode were used; see Figure 17a. As for uniaxial tension, the stress-strain relations are based on trilinear behavior including a linear-elastic loading branch, a linear softening branch and a residual stress plateau, required for the stability of the numerical solution; see Figure 17b.

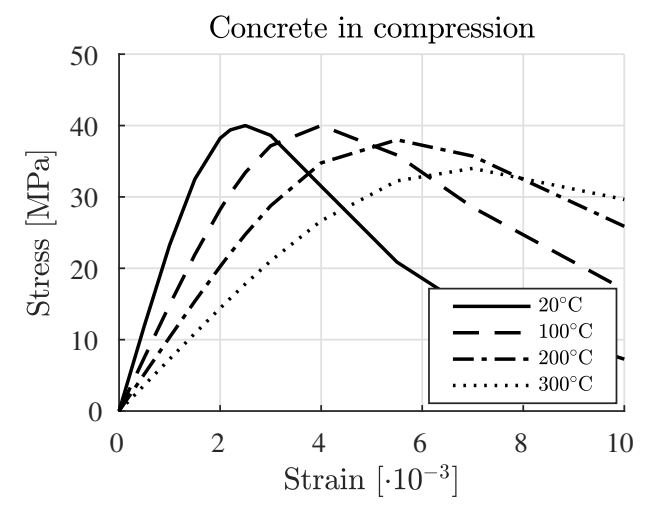

(a)

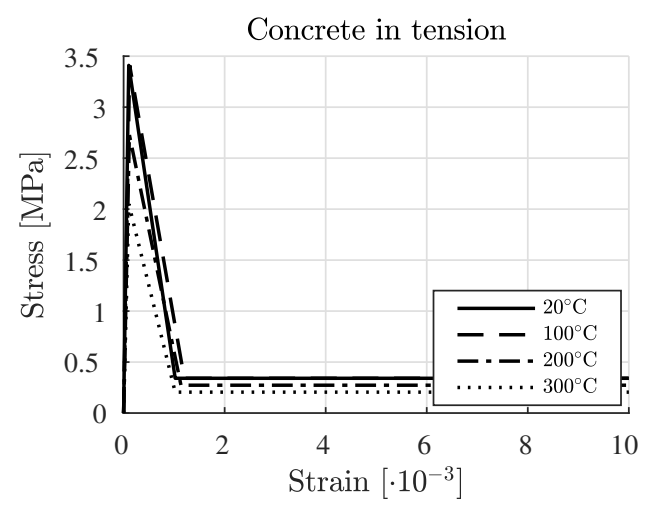

(b)

Figure 17. Temperature-dependent stress-strain relations recommended by Eurocode 2 for concrete subjected to uniaxial (a) compression and (b) tension.

As for the steel rebar, the employed Finite Element program requires specification of the material behavior under uniaxial tension. Up to a temperature of $100{ }^{\circ} \mathrm{C}$, the material is linear-elastic and ideal-plastic; see Figure 18. At higher temperatures, the elastic limit of steel is decreasing, resulting in a trilinear stress-strain curve [43], representing linear-elastic, linear-hardening and ideal-plastic behavior; see Figure 18. The behavior of steel in compression is obtained by multiplying the numbers on the ordinate in Figure 18 by -1 . 


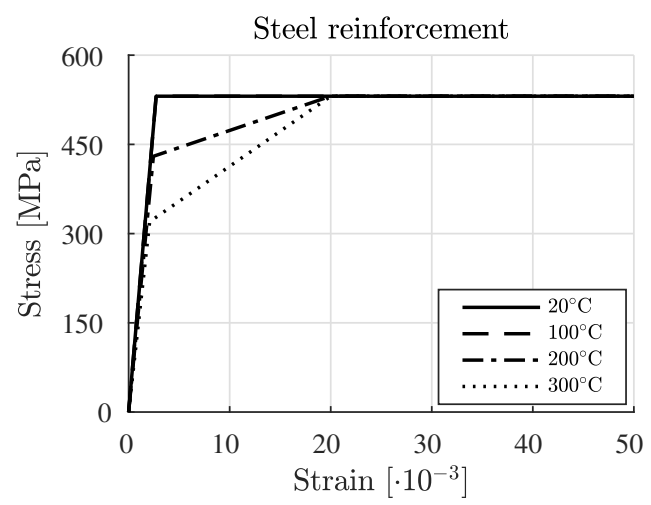

Figure 18. Temperature-dependent behavior of steel rebar subjected to uniaxial tension, as recommended by Eurocode 2.

\subsection{Simulation Results and Comparison with Experimental Data}

The comparison of experimental data and simulation results concerns the total strains at the inner and the outer reinforcement at the midspan of the left cell of the top slab and at the outer reinforcement at the center of the right wall; see Figure 19.

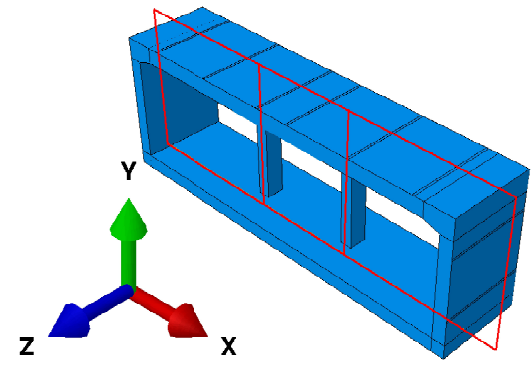

(a)

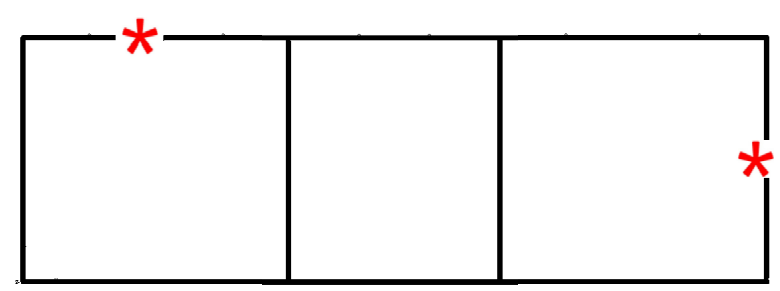

(b)

Figure 19. Positions at which measurements of strains were carried out during testing: (a) perspective representation and (b) cross-section, coinciding with the plane of symmetry of the structure that contains the columns.

\subsection{Structural Response under Mechanical Loading}

Experimental data and simulation results referring to the state after the application of the external loading, but before the application of the thermal loading are compared in the following. As regards the numerical results, there are strains from two simulations: one is based on the linear-elastic (label: LE) and the other one on the elasto-plastic (label: EP) material behavior of concrete.

The two simulations produce similar results; see Table 8 . The EP simulation delivers strains that are by less than $3.5 \%$ larger than the strains from the LE simulation. This indicates that linear-elastic behavior of concrete governed the structural performance during and right after the application of the external loading, while inelastic effects played a significantly less important role.

Both types of simulations delivered strains that agree with the measurements in terms of the mathematical sign, referring to tensile and compressive strains, respectively; see Table 8 . Satisfactory agreement between simulation results and experimental data was obtained for the right wall. There, the difference between simulated and measured strains amounted to $3.0 \times 10^{-6}$ (LE simulation) and $1.4 \times 10^{-6}$ (EP simulation). This is equivalent to prediction errors of $6.1 \%$ and $2.8 \%$, respectively. The absolute and relative differences at the other two positions, however, were significantly larger; see the last two columns of Table 8 . These differences could be the result either of inaccurate measurements or of damage of the structure prior to testing. The latter could have resulted from restrained shrinkage of concrete or from the transport and maneuvering of the structure. 
Table 8. Measured and simulated strains of steel rebar, positioned at the inner and the outer reinforcement at midspan of the left cell of the top slab and at the outer reinforcement at the center of the right wall: additional strains, resulting from application of the mechanical loading, considering linear-elastic (LE) or elasto-plastic (EP) material behavior of concrete.

\begin{tabular}{cccc}
\hline Analysis Type & RW Outer Layer $\left(\mathbf{1 0}^{-\mathbf{6}}\right)$ & TS Outer Layer $\left(\mathbf{1 0}^{\mathbf{- 6}}\right)$ & TS Inner Layer $\left(\mathbf{1 0}^{\mathbf{- 6}}\right)$ \\
\hline Measured & -48.9 & -49.4 & 3.72 \\
LE & -45.9 & -68.9 & 29.2 \\
EP & -47.6 & -69.4 & 30.1 \\
\hline
\end{tabular}

\subsection{Structural Response under Thermomechanical Loading}

The comparison of experimental data and simulation results refers to the strain increments caused by the application of the thermal loading. As regards the numerical results, there are strain increments from four different simulations. They refer either to the linear-elastic (label: LE) or to the elasto-plastic (label: EP) material behavior of concrete and either to a spatially-uniform prescription of one surface temperature history (label: $\mathrm{U}$ ) or to a piecewise spatially-uniform prescription of three different surface temperature histories (label: P).

As regards the outer reinforcement both at the midspan of the left cell of the top slab and at the center of the right wall, the two different types of thermal boundary conditions have little influence on the simulation results; see Figure 20a,c. This follows from the fact that the outer reinforcement layers were not experiencing a temperature change during the experiment. The material model used for concrete, in turn, has a much larger influence. The linear-elastic model results in larger strain increments as compared to the elasto-plastic model. The differences increase with increasing duration of the thermal loading, and they are larger at the top slab as compared to the right wall; compare Figure 20a,c. In addition, both types of simulations underestimate the measured strain increments.

In this context, the uncertainties regarding the thermal boundary conditions and the material behavior of concrete must be mentioned. On the one hand, there are strong indications that the inner surface of the tested structure was exposed to significant temperature gradients. Given that there were only two thermocouples positioned very close to the heated surface, the thermal boundary conditions are affected by considerable uncertainties. On the other hand, the material behavior of concrete was accounted for as suggested by current standards and pertinent guidelines. Nevertheless, some aspects deserve special attention. It is likely that concrete was damaged prior to testing because of restrained shrinkage. Moreover, time-dependent viscous material behavior in the form of creep and load induced-thermal strains (LITS) could also have influenced the structural performance considerably.

As regards the inner reinforcement at the midspan of the left cell of the top slab, the differences of the strain increments obtained with different thermal boundary conditions are significantly larger than described above; compare Figure 20b with Figure 20a,c. This follows from the fact that the inner reinforcement layers were experiencing a significant temperature change during the experiment. It is also interesting to note that the elasto-plastic simulations deliver larger strains than the linear-elastic simulations. This indicates that inelastic material behavior of concrete, in particular tensile cracking, had a significant influence on the structural performance during the fire test. 


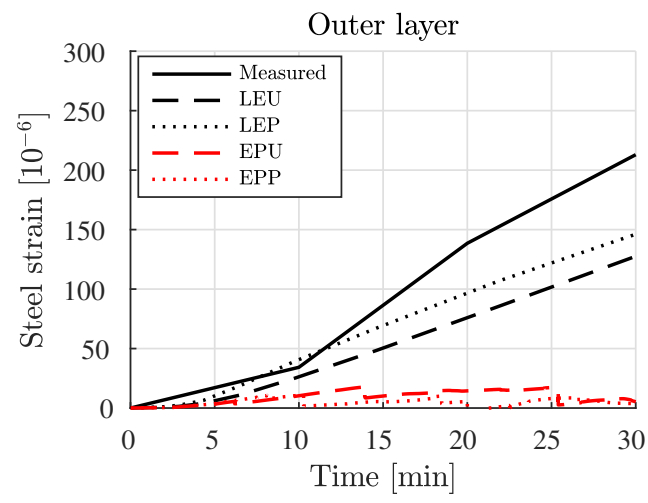

(a)

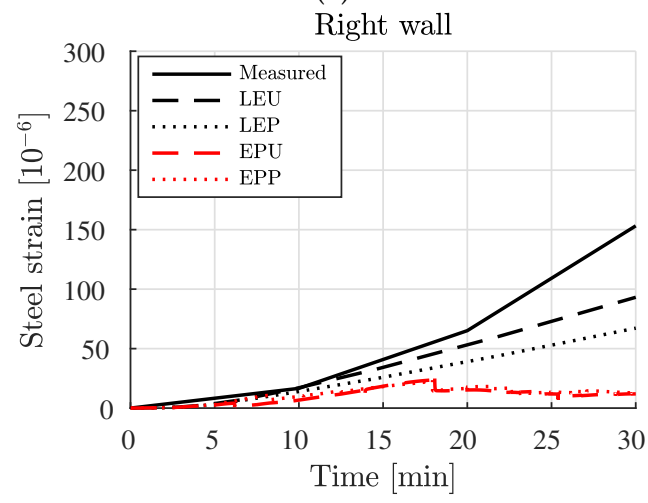

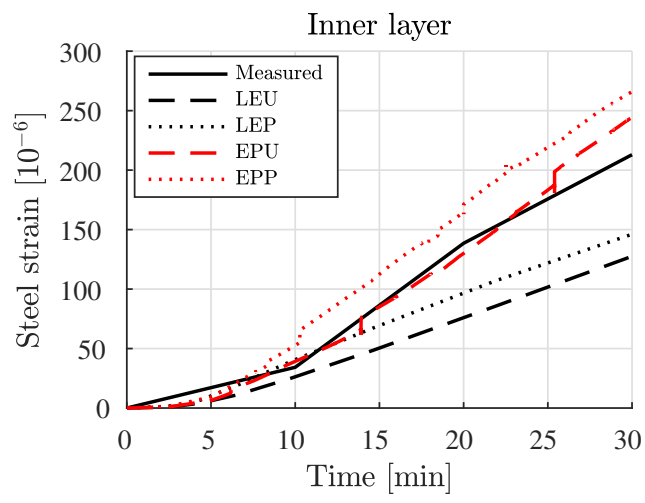

(b)

(c)

Figure 20. Measured and simulated strains of steel rebar: (a) outer and (b) inner reinforcement at the midspan of the left cell of the top slab, and (c) outer reinforcement at the center of the right wall: strain increments, resulting from application of the thermal loading, considering linear-elastic (LE) or elasto-plastic (EP) material behavior of concrete and a prescription of one uniform surface temperature history $(\mathrm{U})$ or of three different piecewise uniform surface temperature histories $(\mathrm{P})$.

The elasto-plastic material model for concrete improved the quality of the simulations, albeit with a significant increase in computational effort. The brittle nature of the structure caused abrupt local failures in specific regions where the tensile stresses were particularly large; see Figures 21-26. The figures show states of the structure separated by less than $0.2 \mathrm{~s}$. This sudden loss of strength caused numerical problems. In order to overcome these problems by means of numerical simulations, fictitious stabilizing viscous forces were introduced, following the recommendations of Abaqus FEA, in order to redistribute the stresses near the affected regions smoothly. The quality of the results was nevertheless verified by comparing the magnitude of these fictitious viscous forces with the total magnitude of the acting forces. Additionally, the ratio of the energy introduced by these forces (also referred to as "static dissipation energy" [42]) to the total internal energy was verified as remaining below $5 \%$ at all times. 

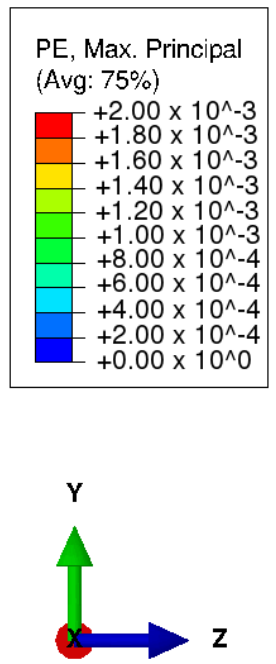

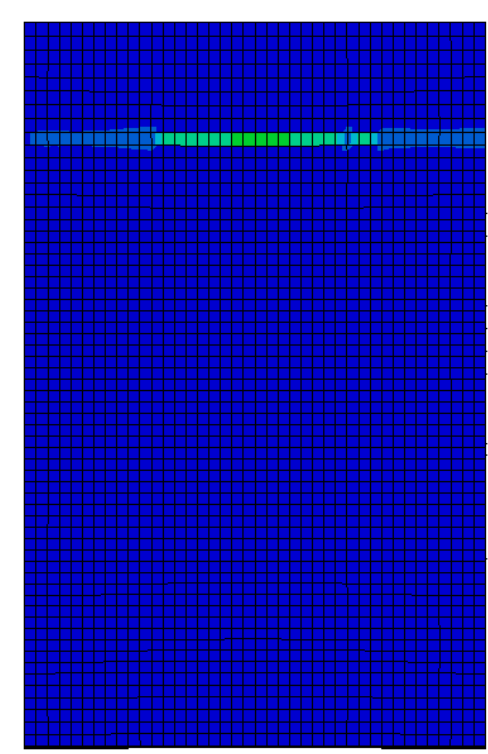

Figure 21. Plastic strains, developed on the outer surface of the top slab at its connection to the lateral wall right before the onset of cracking, as obtained from a thermomechanical simulation based on temperature-dependent and elasto-plastic material behavior, as well as on the prescription of one uniform surface temperature history; the results refer to the time instant six minutes and $3.4 \mathrm{~s}$ after the beginning of the fire test.
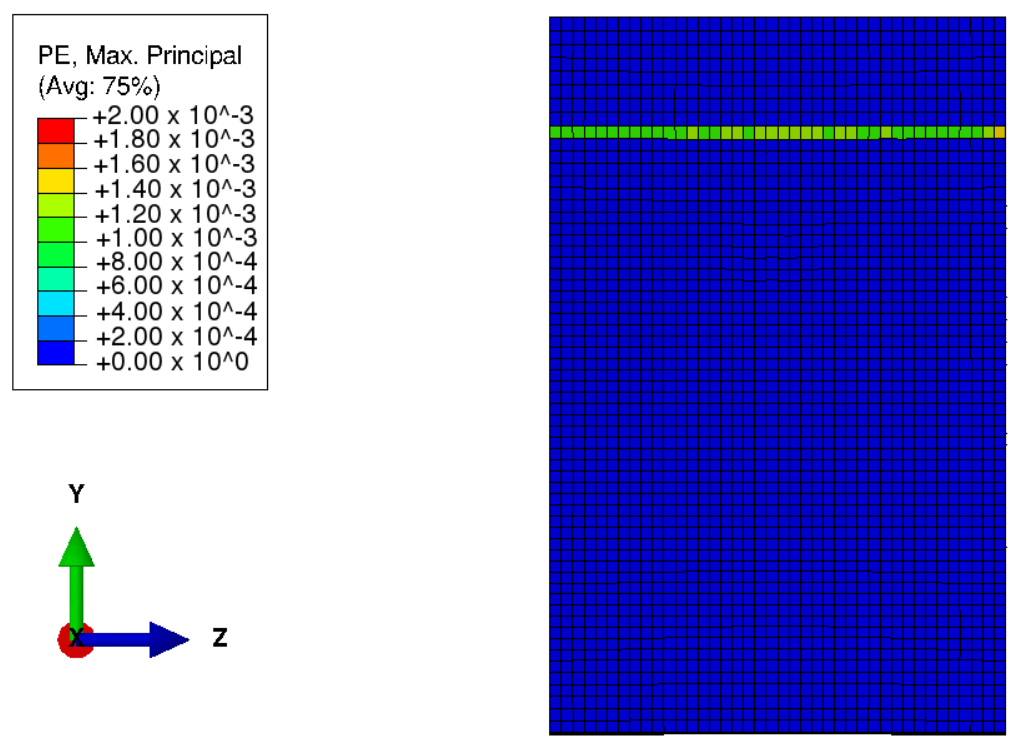

Figure 22. Plastic strains, developed on the outer surface of the top slab at its connection to the lateral wall right after the onset of cracking, as obtained from a thermomechanical simulation based on temperature-dependent and elasto-plastic material behavior, as well as on the prescription of one uniform surface temperature history; the results refer to the time instant 6 min and $3.6 \mathrm{~s}$ after the beginning of the fire test. 

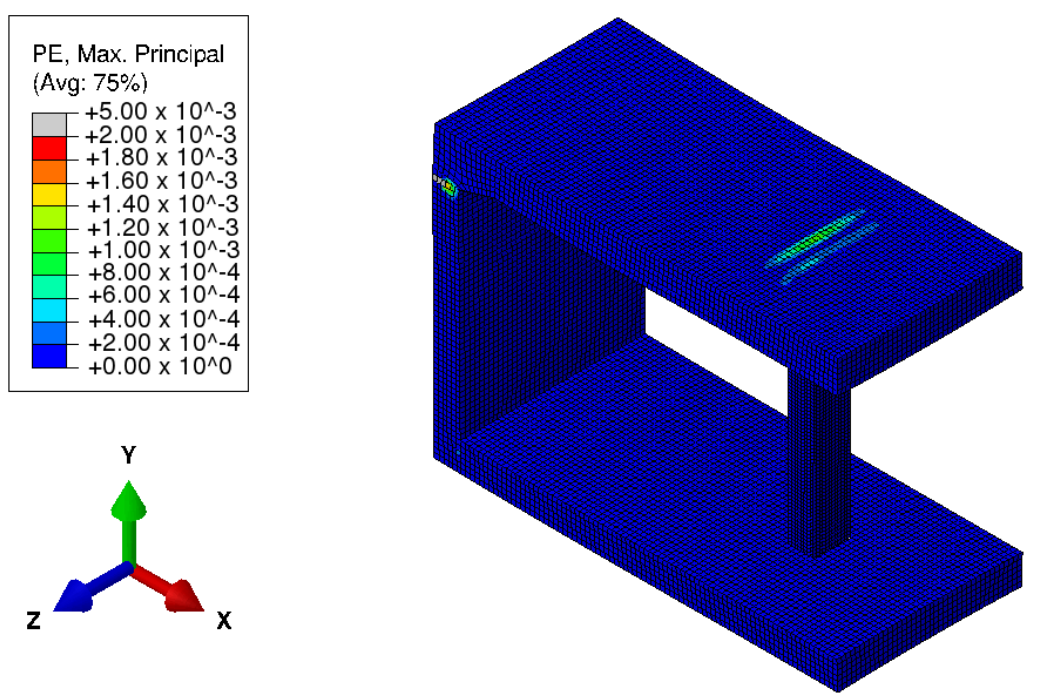

Figure 23. Plastic strains, developed on the outer surface of the top slab at its connection to the column right before the onset of cracking, as obtained from a thermomechanical simulation based on temperature-dependent and elasto-plastic material behavior, as well as on the prescription of one uniform surface temperature history; the results refer to the time instant $13 \mathrm{~min}$ and $50.5 \mathrm{~s}$ after the beginning of the fire test.
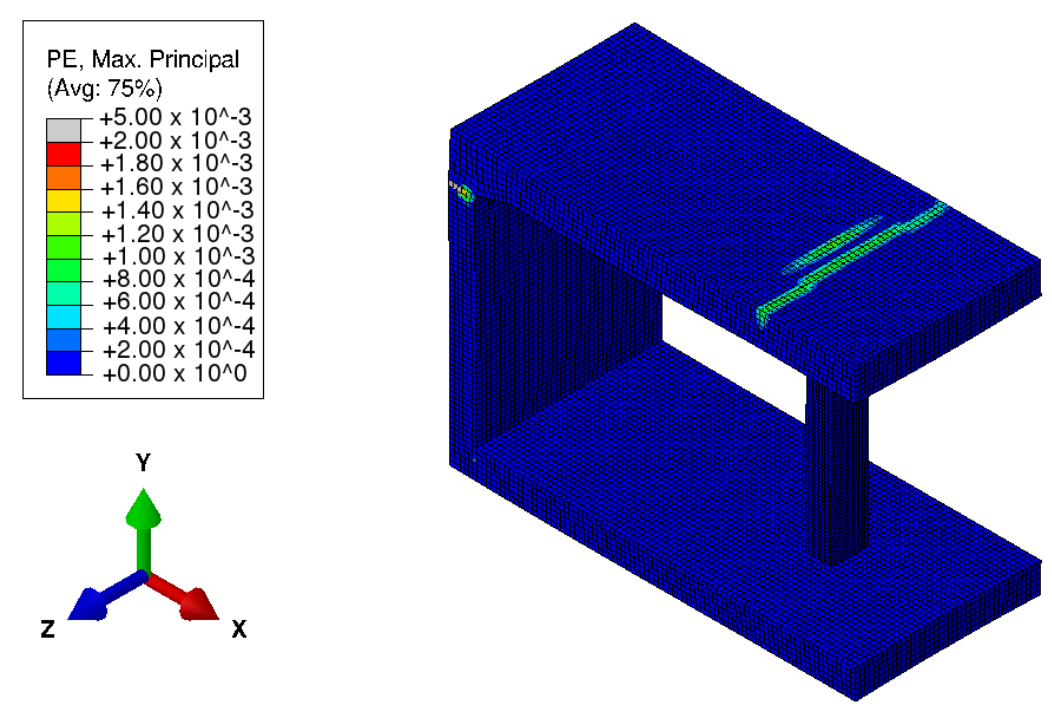

Figure 24. Plastic strains, developed on the outer surface of the top slab at its connection to the column right after the onset of cracking, as obtained from a thermomechanical simulation based on temperature-dependent and elasto-plastic material behavior, as well as on the prescription of one uniform surface temperature history; the results refer to the time instant $13 \mathrm{~min}$ and $50.7 \mathrm{~s}$ after the beginning of the fire test. 

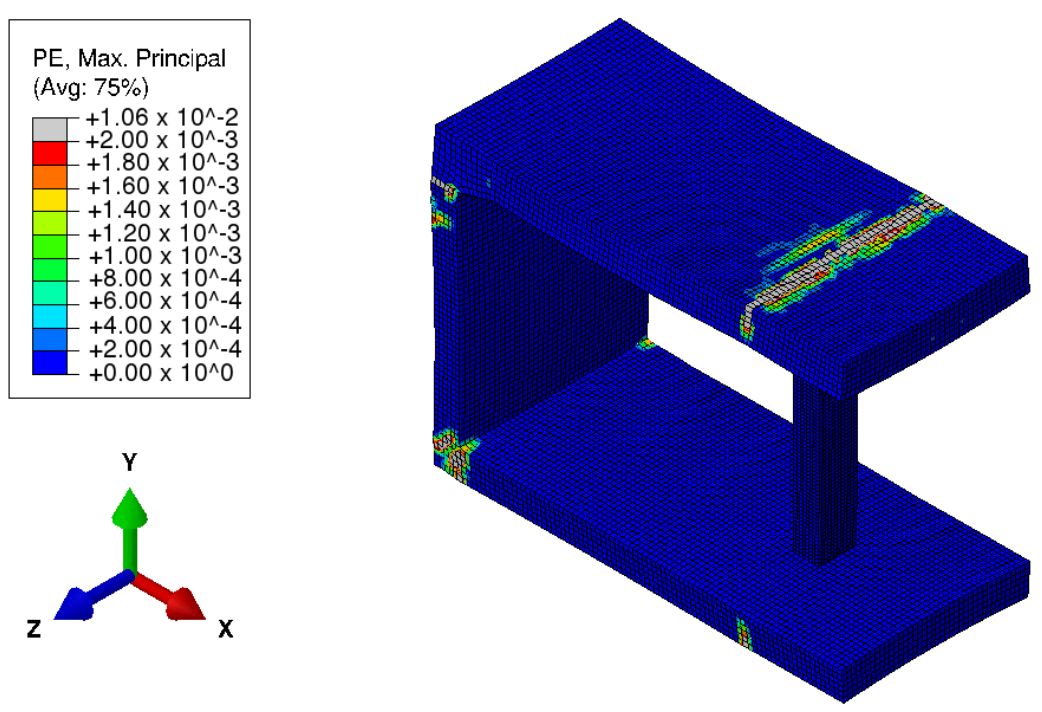

Figure 25. Plastic strains, developed on the outer surface of the top slab at its connection to the column right before the onset of cracking, as obtained from a thermomechanical simulation based on the temperature-dependent and elasto-plastic material behavior, as well as on the prescription of one uniform surface temperature history; the results refer to the time instant $25 \mathrm{~min}$ and $1.0 \mathrm{~s}$ after the beginning of the fire test.
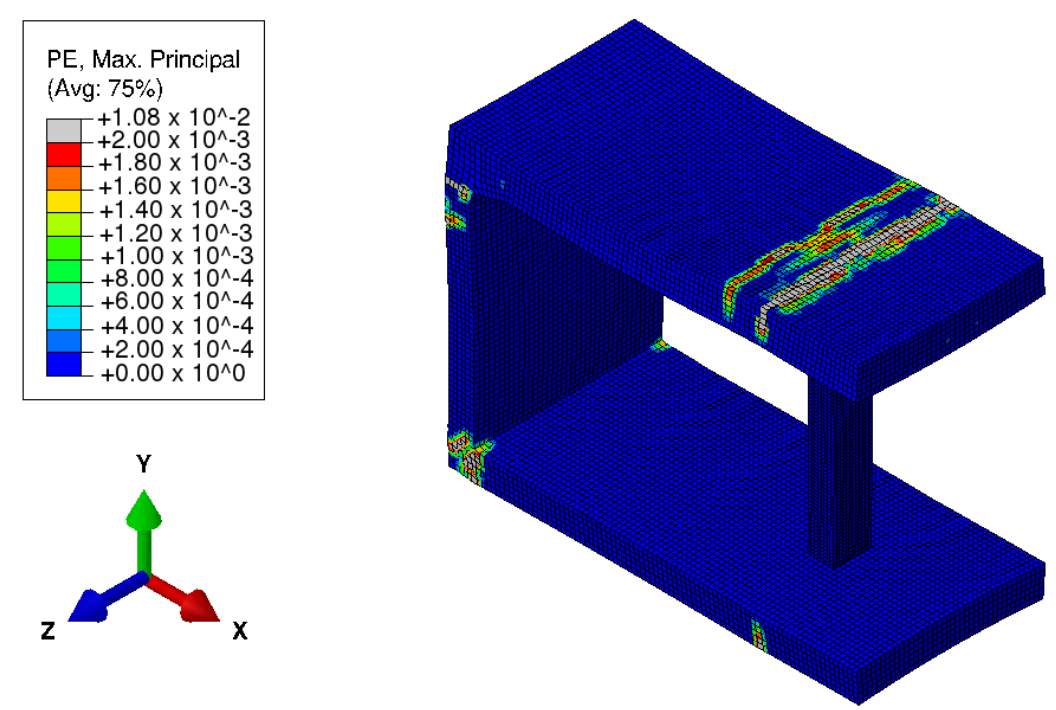

Figure 26. Plastic strains, developed on the outer surface of the top slab at its connection to the column right after the onset of cracking, as obtained from a thermomechanical simulation based on temperature-dependent and elasto-plastic material behavior, as well as on the prescription of one uniform surface temperature history; the results refer to the time instant $25 \mathrm{~min}$ and $1.2 \mathrm{~s}$ after the beginning of the fire test.

\section{Conclusions}

Because moderate fires happen much more frequently than fire disasters [41], the first 30 min of a fire test were analyzed. Sensitivity analyses by means of three-dimensional Finite Element simulations were used to address two specific challenges related to the prediction of the structural performance of a reinforced concrete segment of a subway station. These challenges are:

1. the estimation of the spatial and temporal development of the temperature within the reinforced concrete structure and 
2. the choice of a suitable material model for concrete subjected to mechanical loads and elevated temperatures.

Experimental data from a scaled fire test of an underground substructure by Lu et al. [40] were used as the reference for comparison with the numerical results. From these results, the following conclusions and remarks may be extracted:

- Even under controlled laboratory conditions, different temperatures were measured at equal depths, but at different positions of the tested structure. This underlines significant uncertainties related to the interaction of the hot gas and the surface of the exposed structure. As emphasized by Achenbach et al. [62], these uncertainties can hardly be reduced.

- The temperature within the concrete and the steel elements at all positions at which thermocouples were placed, both in the slabs and the walls, remained below $100{ }^{\circ} \mathrm{C}$ during the first $30 \mathrm{~min}$ of the fire test. Thus, the material properties of concrete and steel remained approximately constant at these positions. This was the motivation to consider the temperature-independent and linear-elastic material behavior of concrete.

- The numerical simulations clarified that the monitored column was exposed to significantly higher temperatures than the slabs and the walls. This was probably a result of the fact that the columns were positioned above the two heat sources of the furnace. Because of the elevated temperatures, a considerable thermal degradation of the material properties of concrete and steel took place in the columns.

- The strain measurements clarified that strains resulting from the thermal loading dominate the total strains soon after the beginning of the fire. This underlines that even moderate fires do represent a considerable threat to the integrity and durability of RC structures.

The challenge of the three-dimensional simulation was met in two parts. At first, the non-stationary heat transfer inside the reinforced concrete structure was simulated. The obtained temperature field histories were used as input for subsequent simulations of the load-carrying behavior of the reinforced concrete structure. Two types of thermal boundary conditions were combined with two types of material models for concrete.

The following conclusions are drawn from the two different types of heat transfer simulations:

- The prescription of one uniform temperature history at all exposed surfaces does not produce convincing results. Temperature measurements are particularly underestimated inside the right column and at the midspan of the left cell of the top slab.

- The prescription of three different piecewise uniform temperature histories showed that, provided the temperature history at a specific surface is known and used as the local thermal boundary condition, the ingress of heat at that position of the structure is predicted accurately.

- The surface temperature histories were only measured at two positions of the tested structure. Thus, assumptions concerning the thermal boundary conditions were indispensable for the numerical simulations. They are anyway questionable, because the unsolved problem of the dynamics of flames remains an important source of uncertainty; see, e.g., the study by Blanchard et al. [34].

- The simulation with the improved thermal boundary conditions underlined that the temperature increase at the surface of the columns is expected to be larger than $280{ }^{\circ} \mathrm{C}$. Thus, thermal degradation of the mechanical properties of concrete and steel occurs. This was the motivation to consider the temperature-dependent and elasto-plastic material behavior of concrete.

The following conclusions are drawn from the four different types of thermomechanical simulations of the load-carrying behavior of the analyzed structure:

- The load-carrying behavior of the structure, when subjected to mechanical loads only, was governed by linear-elastic material behavior. Although tensile cracking took place at several positions of the structure, inelastic material behavior did not play an important role. 
- The numerical simulations referring to the mechanical loading reproduced strain measurements that were only reliable at the right wall, whereas the absolute values of the strains at midspan of the left cell of the top slab were overestimated significantly. This has revealed two additional sources of uncertainty, namely the reliability of measurements and the initial state of the structure. It is likely that the highly statically indeterminate structure was damaged already before the test, by restrained shrinkage of concrete and by the transport of the structure from the production site to the test furnace.

- The numerical simulations referring to the mechanical and the thermal loading reproduced strain measurements that were only reliable at the inner reinforcement at the midspan of the left cell of the top slab, whereas the absolute values of the strains at the other two positions at which strain measurements were available were underestimated significantly. The best results were obtained from the most realistic simulation, based on the prescription of three different piecewise uniform surface temperature histories, as well as on temperature-dependent elasto-plastic behavior of concrete.

The Finite Element simulations provide insight into the structural behavior of the tested segment of a subway station. From the numerical results obtained with the nonlinear material model for concrete, the following conclusions are drawn:

- Already moderate fires threaten the integrity of RC structures. As for the analyzed structure, the Finite Element simulations indicate localized tensile cracking at the outer surface of the structure, in regions where the top and the bottom slabs are connected to the walls and the columns; see Figures 21-26. In more detail, the Finite Element simulations indicate that the corners, i.e., the connections between the walls and the slabs, were damaged first (Figures 21 and 22), followed by a localized damage of the slabs, in the immediate vicinity of the connections to the columns (Figures 23-26).

- Tensile cracking of concrete and the associated redistribution of stresses within the RC structure take place in a quasi-instantaneous fashion. This renders numerical stabilization approaches indispensable in order to achieve convergence in nonlinear Finite Element simulations.

- Careful inspection of RC structures is strongly recommended also after moderate fire events (see, e.g., the methods proposed by Felicetti [63]), even if the accessible interior surface of an underground structure appears to be undamaged.

- Connections between structural elements with strong differences regarding the ratio between their heat-exposed surface and their volume are prone to suffer from localized damage. Notably, columns tend to exhibit larger surface-to-volume ratios than slabs and walls. Thus, connections between columns and slabs should be thoroughly inspected.

- Tensile cracking of the inaccessible exterior surface of an underground structure is a serious threat for the long-term durability of the structure after the fire, because the cracks represent pathways for substances that promote the corrosion risk/rate of the steel rebar.

As for future fire tests, the following recommendations can be made based on the results of the present study:

- It is recommended to carry out test repetitions, also in the context of structural experiments, even though such tests are time-consuming and expensive. Test repetitions render the desirable assessment of the experimental scatter associated with the chosen testing method possible; see, e.g., the experimental approach by Schlappal et al. [64].

- It is recommended to carry out redundant measurements of key quantities. This implies that key quantities shall be measured by two independent test methods. The availability of redundant measurements allows for the assessment of the reliability of the used measurement equipment; see, e.g., the experimental approach by Wyrzykowski et al. [65].

- When it comes to the design of a large fire test, it is recommended to position many thermocouples close to the heated surface in order to gain access to the spatial distribution 
of the surface temperature histories. This way, the uncertainties of the actual fire load can be reduced significantly.

- It is recommended to produce test structures at the place and in the position of subsequent fire testing, such that possible damage associated with the transport and the maneuvering of the structure can be excluded.

- It is recommended to equip the tested reinforced concrete structure with embedded sensors that allow for quantification of possible damage of the structure resulting from restrained shrinkage. As for the design of such embedded sensors, multi-physics simulations of the structure, providing insight into the performance of the structure from its production, throughout all early-age stages, all the way up to the time of testing, are needed. This requires a strong investment of the global scientific community into basic research, aimed at a better understanding of structures made from modern concretes.

Author Contributions: Conceptualization, Bernhard Pichler. Formal analysis, R.D. Investigation, R.D. and H.W. Supervision, B.P. Writing, original draft, R.D. Writing, review and editing, H.W., H.M., Y.Y. and B.P.

Funding: Financial support was provided by the Austrian Science Fund (FWF), within the project P 281 31-N32 "Bridging the Gap by Means of Multiscale Structural Analyses". The second author also gratefully acknowledges financial support by the China Scholarship Council (CSC).

Conflicts of Interest: The authors declare no conflict of interest. The founding sponsors had no role in the design of the study; in the collection, analyses or interpretation of data; in the writing of the manuscript; nor in the decision to publish the results

\section{Appendix A. Temperature Distribution Inside the Concrete Structure}

Simulation results in regions of the structure which were not equipped with thermocouples are presented and discussed in the following. As regards the heat transfer in the analyzed structure, it can be noted that:

- During the first $30 \mathrm{~min}$ of the fire test, the temperature of the reinforced concrete structure increased up to a distance of some $10 \mathrm{~cm}$ from the heated surface, see Figures A1-A3.

- One-dimensional heat conduction occurs in the top slab, the bottom slab, and the lateral walls, except in the immediate vicinity of the columns and the walls, see Figures A1 and A2. Notably, the one-dimensional heat transfer problems could also be solved in a semi-analytical fashion, following e.g., Wang et al. [66].

- Two-dimensional heat conduction occurs in the columns (Figures 13 and 15) and in the vicinity of the connections of the slabs with the columns and the walls. As for studying the heat transfer in these regions, Finite Element simulations are indispensable for reliable results.

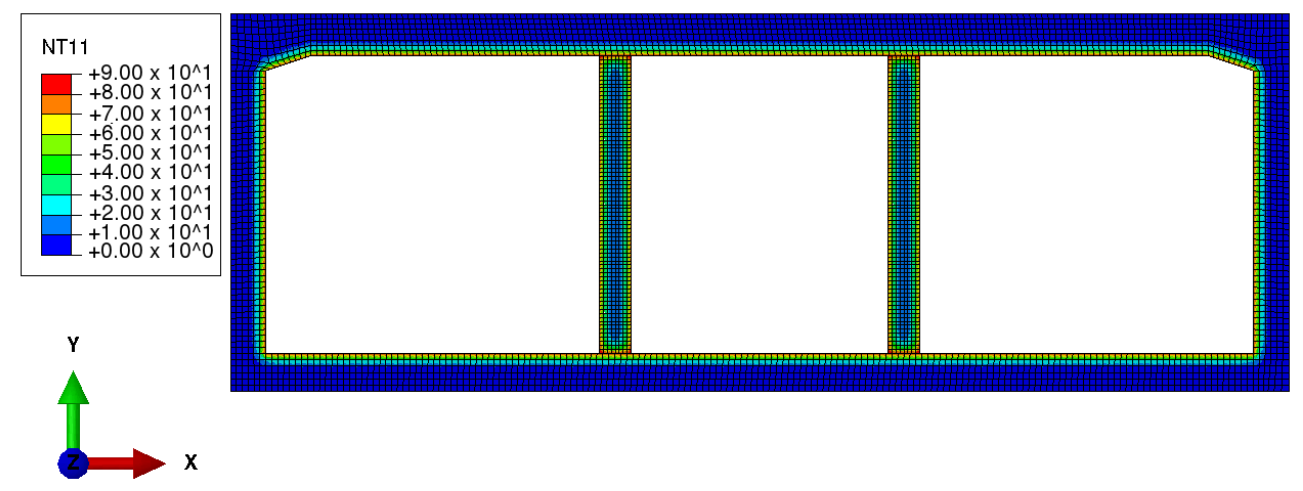

Figure A1. Temperature distribution obtained by prescribing a uniform surface temperature history, $30 \mathrm{~min}$ after the start of the thermal loading: overview over the whole structure. 


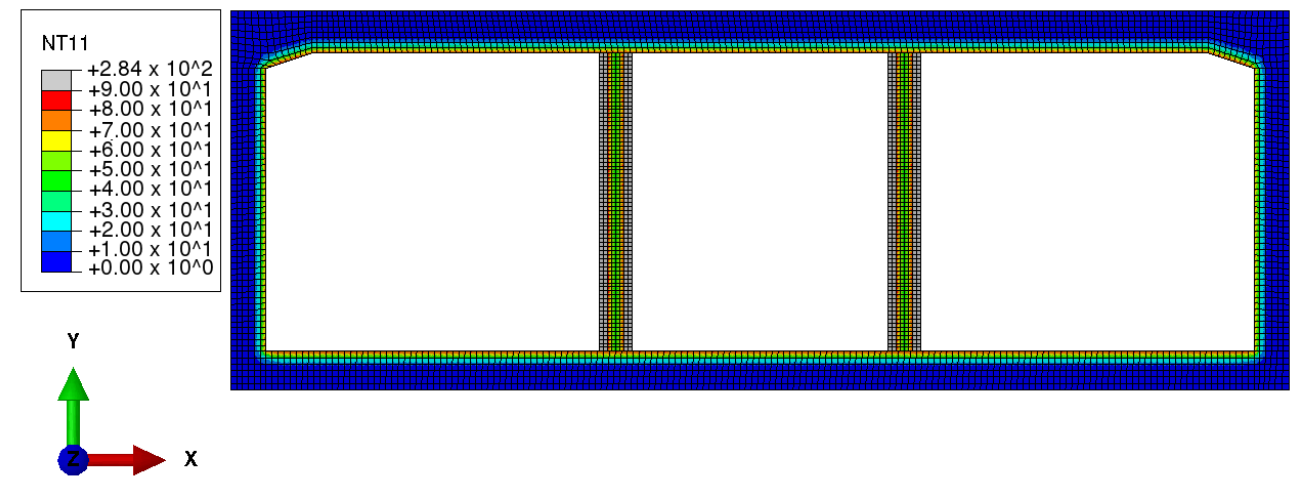

Figure A2. Temperature distribution obtained by prescribing three piecewise uniform surface temperature histories, $30 \mathrm{~min}$ after the start of the thermal loading: overview over the whole structure.
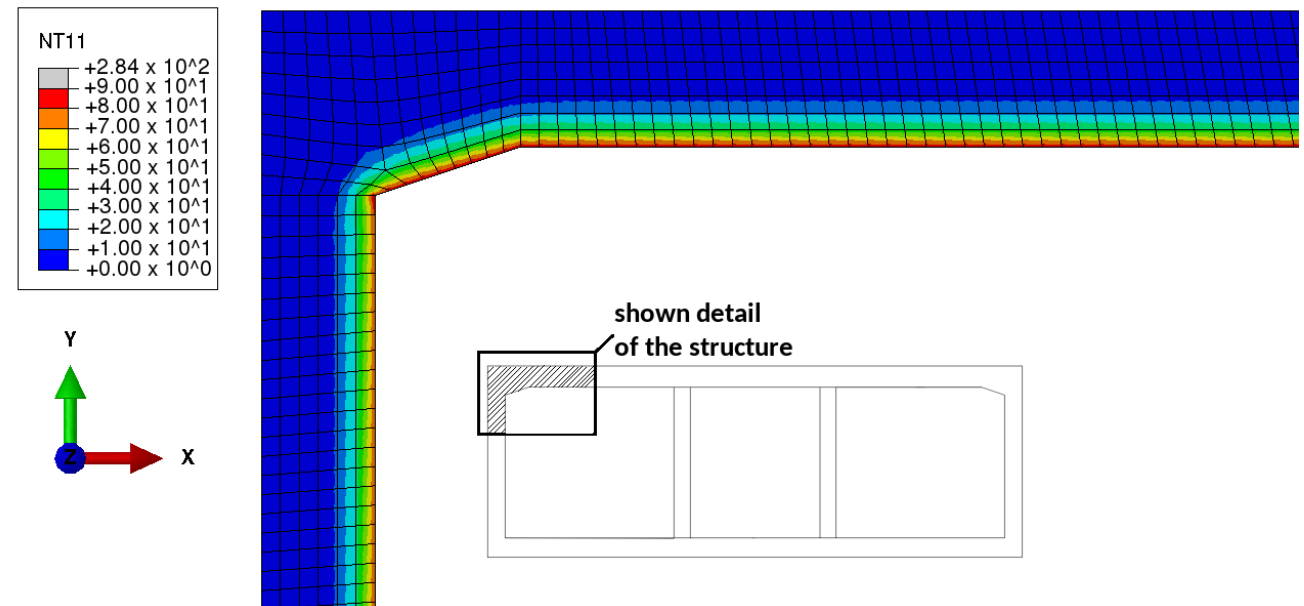

Figure A3. Temperature distribution obtained by prescribing three piecewise uniform surface temperature histories, $30 \mathrm{~min}$ after the start of the thermal loading: detail showing the connection of the left wall to the top slab.

\section{Appendix B. Elasto-Plastic Material Model for Concrete}

The "Concrete Damaged Plasticity" model of Abaqus [42] was used. A theoretical description of the model is presented in this appendix. The terms used by Abaqus are adopted in order to facilitate the application of this computer program. The constitutive model is essentially based on work by Lubliner at al. [67]. The plasticity part of the model controls the evolution of the yield stress of concrete. Thus, it refers to the strength of concrete. The damage part refers to the stiffness of concrete. It is designed to model the degradation of Young's modulus, resulting from mechanical loading. This is particularly important if concrete is unloaded in the process of softening. In this context, it is noteworthy that the challenge of the present simulation refers to an experiment, in which an increase of mechanical loading is followed by an increase of thermal loading. Thus, the damage part of the model remains inactive without reduction of the informative content of the simulation. Additionally, because the damage part is not used, there is no need to distinguish between Cauchy stresses and "effective stresses", between the "tensile cracking strain" and the plastic strain, as well as the "compressive inelastic strain" and the plastic strain, mentioned in the manual of Abaqus FEA.

The employed material model accounts for two failure mechanisms: tensile cracking and compressive crushing. As input, it requires the definition of stress-strain relationships for uniaxial compression and uniaxial tension, respectively.

As for uniaxial compression, the input required by Abaqus FEA consists of look-up tables that list pairs of values of the "yield stress" and the "inelastic strain", and these listings are specified for different temperatures. The "yield stress" is equal to (i) the imposed stress, in the region of initial 
elastic loading, (ii) the uniaxial elastic-limit stress, in the region of pre-peak hardening, (iii) the uniaxial compressive strength, at the peak, and (iv) the residual uniaxial compressive strength, in the region of post-peak softening. In the present context, the "inelastic strain" is simply equal to the plastic strain, given that the damage part remains unused. The used look-up tables are based on stress-strain regulations of the Eurocode, see Figure 17a. Thereby, the term "strain" refers to the total strain, $\varepsilon$, which is the sum of the elastic strain $\varepsilon^{e l}$, and the plastic strain, $\varepsilon^{p l}$ :

$$
\varepsilon=\varepsilon^{e l}+\varepsilon^{p l} .
$$

The elastic strain follows from Hooke's law as:

$$
\varepsilon^{e l}=\frac{\sigma}{E_{c}(T)},
$$

where $E_{\mathcal{c}}(T)$ denotes the temperature-dependent Young's modulus of concrete. The plastic strains, required for the look-up tables, result from inserting Equation (A2) into Equation (A1), and solving the resulting expression for $\varepsilon_{c}^{p l}$ as:

$$
\varepsilon^{p l}=\varepsilon-\frac{\sigma}{E_{c}(T)},
$$

see Table A1.

As for uniaxial tension, the used look-up tables are based on trilinear stress-strain behavior including a linear-elastic loading branch, a linear softening branch, and a residual stress plateau, required for the stability of the numerical simulation, see Figure 17b. Thereby, the term "strain" refers to the total strain. By analogy to the previously described procedure for uniaxial compression, the plastic tensile strains required for the look-up tables results from Equation (A3).

\begin{tabular}{|c|c|}
\hline Yield Stress (MPa) & Inelastic Strain $\left(10^{-3}\right)$ \\
\hline \multicolumn{2}{|r|}{$\mathbf{a}$} \\
\hline 23.6 & 0.0 \\
\hline 32.5 & 0.5 \\
\hline 38.2 & 0.9 \\
\hline 39.4 & 1.0 \\
\hline 40.0 & 1.3 \\
\hline 38.6 & 1.8 \\
\hline 31.5 & 3.1 \\
\hline 20.9 & 4.9 \\
\hline 14.3 & 6.6 \\
\hline 7.3 & 9.8 \\
\hline \multicolumn{2}{|r|}{ b } \\
\hline 21.9 & 0.7 \\
\hline 28.2 & 1.0 \\
\hline 30.5 & 1.1 \\
\hline 33.4 & 1.3 \\
\hline 37.1 & 1.7 \\
\hline 40.0 & 2.6 \\
\hline 35.9 & 4.2 \\
\hline 28.5 & 6.0 \\
\hline 17.0 & 9.4 \\
\hline
\end{tabular}

Table A1. Input values for compressive behavior at (a) room temperature, (b) $100{ }^{\circ} \mathrm{C}$, (c) $200{ }^{\circ} \mathrm{C}$, (d) $300{ }^{\circ} \mathrm{C}$. 
Table A1. Cont.

\begin{tabular}{|c|c|}
\hline Yield Stress (MPa) & Inelastic Strain $\left(10^{-3}\right)$ \\
\hline \multicolumn{2}{|r|}{ c } \\
\hline 10.3 & 0.0 \\
\hline 15.4 & 0.9 \\
\hline 20.2 & 1.2 \\
\hline 22.1 & 1.3 \\
\hline 24.7 & 1.5 \\
\hline 28.8 & 1.8 \\
\hline 34.8 & 2.6 \\
\hline 38.0 & 3.9 \\
\hline 35.7 & 5.5 \\
\hline 25.9 & 8.9 \\
\hline \multicolumn{2}{|r|}{$\mathrm{d}$} \\
\hline 7.3 & 0.0 \\
\hline 10.9 & 1.0 \\
\hline 14.4 & 1.3 \\
\hline 15.8 & 1.4 \\
\hline 17.8 & 1.6 \\
\hline 21.0 & 1.9 \\
\hline 26.7 & 2.7 \\
\hline 32.2 & 3.9 \\
\hline 34.0 & 5.3 \\
\hline 29.6 & 8.5 \\
\hline
\end{tabular}

Table A2. Input values for tensile behavior at a) room temperature, (b) $100{ }^{\circ} \mathrm{C}$, (c) $200{ }^{\circ} \mathrm{C}$, (d) $300{ }^{\circ} \mathrm{C}$.

\begin{tabular}{|c|c|}
\hline Yield Stress (MPa) & Cracking Strain $\left(10^{-3}\right)$ \\
\hline \multicolumn{2}{|r|}{ a } \\
\hline 3.41 & 0.0 \\
\hline 0.34 & 1.02 \\
\hline 0.34 & 10 \\
\hline \multicolumn{2}{|r|}{$\mathbf{b}$} \\
\hline 3.41 & 0.0 \\
\hline 0.34 & 1.20 \\
\hline 0.34 & 10 \\
\hline \multicolumn{2}{|r|}{ c } \\
\hline 2.73 & 0.0 \\
\hline 0.27 & 1.14 \\
\hline 0.27 & 10 \\
\hline \multicolumn{2}{|r|}{ d } \\
\hline 2.05 & 0.0 \\
\hline 0.21 & 1.02 \\
\hline 0.21 & 10 \\
\hline
\end{tabular}

The elasto-plastic classification of multiaxial stress states, defined in terms of Cauchy stress tensors $\underline{\underline{\sigma}}$, is based on the failure surface $F$, reading as [42]:

$$
F(\underline{\underline{\sigma}})=\frac{1}{1-\alpha}\left[q-3 \alpha p+\beta\left(\varepsilon_{c}^{p l}, \varepsilon_{t}^{p l}\right) \cdot\left\langle\sigma_{\max }\right\rangle-\gamma\left\langle\sigma_{\max }\right\rangle\right]-\sigma_{c}\left(\varepsilon_{c}^{p l}\right) \leq 0 .
$$


In Equation (A4) $p$ denotes the hydrostatic pressure:

$$
p=-\frac{\operatorname{tr} \underline{\underline{\sigma}}}{3}
$$

where the symbol "tr" stands for the "trace"-function; $q$ denotes the von Mises stress, given as:

$$
q=\sqrt{\frac{3}{2}(\underline{\underline{s}}: \underline{\underline{s}})},
$$

where $\underline{\underline{s}}$ denotes the stress deviator:

$$
\underline{\underline{s}}=\underline{\underline{\sigma}}+p \underline{\underline{1}}
$$

with $\underline{\underline{1}}$ as the second-order identity tensor. $\sigma_{\max }$ is the maximum principal normal stress. $\sigma_{c}\left(\varepsilon_{c}^{p l}\right)$ is the current value of the "compressive cohesion stress" [42], i.e., the current value of the uniaxial compressive strength. The brackets \langle\rangle stand for the Macaulay brackets, defined as:

$$
\langle x\rangle=\frac{1}{2}(|x|+x) .
$$

The dimensionless constant $\alpha$ is related to the ratio of the elastic limit stresses under symmetric biaxial and uniaxial compressive loading:

$$
\alpha=\frac{\left(\sigma_{b 0} / \sigma_{c 0}\right)-1}{2\left(\sigma_{b 0} / \sigma_{c 0}\right)-1}
$$

The default value of $\sigma_{b 0} / \sigma_{c 0}$ amounts to 1.16 , such that $\alpha=0.12$. The dimensionless parameter $\beta\left(\varepsilon_{c}^{p l}, \varepsilon_{t}^{p l}\right)$ is defined as:

$$
\beta\left(\varepsilon_{c}^{p l}, \varepsilon_{t}^{p l}\right)=(1-\alpha) \frac{\sigma_{c}\left(\varepsilon_{c}^{p l}\right)}{\sigma_{t}\left(\varepsilon_{t}^{p l}\right)}-(1+\alpha),
$$

where $\sigma_{t}\left(\varepsilon_{t}^{p l}\right)$ is the current value of the "tensile cohesion stress" [42], i.e., the current value of the uniaxial tensile strength. $\gamma$ is a constant, controlling the anisotropy of the failure surface in the deviatoric planes:

$$
\gamma=\frac{3\left(1-K_{c}\right)}{2 K_{c}-1}
$$

where $K_{c}$ denotes a dimensionless parameter. Its default value for concrete amounts to 0.67 , such that $\gamma=3$.

The flow rule represents the evolution law for the plastic strains:

$$
\underline{\underline{\dot{\varepsilon}}}^{p l}=\dot{\lambda} \frac{\partial G}{\partial \underline{\underline{\sigma}}^{\prime}},
$$

where $\underline{\underline{\varepsilon}}^{p l}$ is the rate of the plastic strain tensor, $G$ is the plastic potential function, and $\lambda$ is the consistency factor. The plastic potential $G$ of the non-associated plasticity approach reads as [42]:

$$
G(\underline{\underline{\sigma}})=\sqrt{\left(\epsilon \sigma_{t 0} \tan \psi\right)^{2}+q^{2}}-p \tan \psi,
$$

where $\psi$ is the dilatation angle, $\sigma_{t 0}$ is the initial value of the uniaxial tensile strength, and $\epsilon$ is an "eccentricity" parameter. The default values of $\psi$ and $\epsilon$ amount to $30^{\circ}$ and 0.10 , respectively. The present simulations are based on the described default input values, recommended by Lubliner et al. [67], Abaqus FEA [42], and others [68,69], see Table A3. 
Table A3. Values used for the Concrete Damaged Plasticity model from Abaqus FEA [42].

\begin{tabular}{cccccc}
\hline$\psi$ & $\epsilon$ & $\sigma_{b 0} / \sigma_{c 0}$ & $K_{c}$ & $\alpha$ & $\gamma$ \\
\hline $30^{\circ}$ & 0.10 & 1.16 & 0.67 & 0.12 & 3 \\
\hline
\end{tabular}

\section{References}

1. Schneider, U. Concrete at high temperatures-A general review. Fire Saf. J. 1988, 13, 55-68. [CrossRef]

2. Ulm, F.J.; Coussy, O.; Bažant, Z. The "Chunnel” fire. I: Chemoplastic softening in rapidly heated concrete. J. Eng. Mech. 1999, 125, 272-282. [CrossRef]

3. Gawin, D.; Pesavento, F.; Schrefler, B. Modelling of hygro-thermal behaviour of concrete at high temperature with thermo-chemical and mechanical material degradation. Comput. Methods Appl. Mech. Eng. 2003, 192, 1731-1771. [CrossRef]

4. Gawin, D.; Pesavento, F.; Schrefler, B. What physical phenomena can be neglected when modelling concrete at high temperature? A comparative study. Part 2: Comparison between models. Int. J. Solids Struct. 2011, 48, 1945-1961. [CrossRef]

5. Bažant, Z.; Jirásek, M. Temperature effect on water diffusion, hydration rate, creep and shrinkage. In Creep and Hygrothermal Effects in Concrete Structures; Springer: Berlin, Germany, 2018; pp. 607-686.

6. Lamont, S.; Usmani, A.; Drysdale, D. Heat transfer analysis of the composite slab in the Cardington frame fire tests. Fire Saf. J. 2001, 36, 815-839. [CrossRef]

7. Tenchev, R.; Li, L.; Purkiss, J. Finite element analysis of coupled heat and moisture transfer in concrete subjected to fire. Numer. Heat Transf. A Appl. 2001, 39, 685-710. [CrossRef]

8. Chung, J.; Consolazio, G. Numerical modeling of transport phenomena in reinforced concrete exposed to elevated temperatures. Cem. Concr. Res. 2005, 35, 597-608. [CrossRef]

9. Khoury, G.; Grainger, B.; Sullivan, P. Transient thermal strain of concrete: Literature review, conditions within specimen and behaviour of individual constituents. Mag. Concr. Res. 1985, 37, 131-144. [CrossRef]

10. Terro, M. Numerical modeling of the behavior of concrete structures in fire. ACI Struct. J. 1998, 95, $183-193$.

11. Mindeguia, J.C.; Hager, I.; Pimienta, P.; Carré, H.; La Borderie, C. Parametrical study of transient thermal strain of ordinary and high performance concrete. Cem. Concr. Res. 2013, 48, 40-52. [CrossRef]

12. Torelli, G.; Mandal, P.; Gillie, M.; Tran, V.X. Concrete strains under transient thermal conditions: A state-of-the-art review. Eng. Struct. 2016, 127, 172-188. [CrossRef]

13. Ulm, F.J.; Acker, P.; Lévy, M. The "Chunnel" fire. II: Analysis of concrete damage. J. Eng. Mech. 1999, 125, 283-289. [CrossRef]

14. Kalifa, P.; Chéné, G.; Gallé, C. High-temperature behaviour of HPC with polypropylene fibres-From spalling to microstructure. Cem. Concr. Res. 2001, 31, 1487-1499. [CrossRef]

15. Hertz, K. Limits of spalling of fire-exposed concrete. Fire Saf. J. 2003, 38, 103-116. [CrossRef]

16. Diederichs, U.; Schneider, U. Bond strength at high temperatures. Mag. Concr. Res. 1981, 33, 75-84. [CrossRef]

17. Haddad, R.; Al-Saleh, R.; Al-Akhras, N. Effect of elevated temperature on bond between steel reinforcement and fiber reinforced concrete. Fire Saf. J. 2008, 43, 334-343. [CrossRef]

18. Gao, W.; Dai, J.G.; Teng, J.; Chen, G. Finite element modeling of reinforced concrete beams exposed to fire. Eng. Struct. 2013, 52, 488-501. [CrossRef]

19. Franssen, J.M.; Dotreppe, J.C. Fire tests and calculation methods for circular concrete columns. Fire Technol. 2003, 39, 89-97. [CrossRef]

20. Kodur, V.; Cheng, F.P.; Wang, T.C.; Sultan, M. Effect of strength and fiber reinforcement on fire resistance of high-strength concrete columns. J. Struct. Eng. 2003, 129, 253-259. [CrossRef]

21. Kodur, V.; Mcgrath, R. Fire endurance of high strength concrete columns. Fire Technol. 2003, 39, $73-87$. [CrossRef]

22. Kodur, V.; Wang, T.; Cheng, F. Predicting the fire resistance behaviour of high strength concrete columns. Cem. Concr. Compos. 2004, 26, 141-153. [CrossRef]

23. Kodur, V.; Dwaikat, M. A numerical model for predicting the fire resistance of reinforced concrete beams. Cem. Concr. Compos. 2008, 30, 431-443. [CrossRef] 
24. Kodur, V.; Yu, B.; Solhmirzaei, R. A simplified approach for predicting temperatures in insulated RC members exposed to standard fire. Fire Saf. J. 2017, 92, 80-90. [CrossRef]

25. Lura, P.; Terrasi, G. Reduction of fire spalling in high-performance concrete by means of superabsorbent polymers and polypropylene fibers: Small scale fire tests of carbon fiber reinforced plastic-prestressed self-compacting concrete. Cem. Concr. Compos. 2014, 49, 36-42. [CrossRef]

26. Xu, Q.; Han, C.; Wang, Y.C.; Li, X.; Chen, L.; Liu, Q. Experimental and numerical investigations of fire resistance of continuous high strength steel reinforced concrete T-beams. Fire Saf. J. 2015, 78, 142-154. [CrossRef]

27. Yan, Z.G.; Shen, Y.; Zhu, H.H.; Li, X.J.; Lu, Y. Experimental investigation of reinforced concrete and hybrid fibre reinforced concrete shield tunnel segments subjected to elevated temperature. Fire Saf. J. 2015, 71, 86-99. [CrossRef]

28. Nguyen, T.T.; Tan, K.H.; Burgess, I. Behaviour of composite slab-beam systems at elevated temperatures: Experimental and numerical investigation. Eng. Struct. 2015, 82, 199-213. [CrossRef]

29. Annerel, E.; Lu, L.; Taerwe, L. Punching shear tests on flat concrete slabs exposed to fire. Fire Saf. J. 2013, 57, 83-95. [CrossRef]

30. Li, G.Q.; Zhang, N.; Jiang, J. Experimental investigation on thermal and mechanical behaviour of composite floors exposed to standard fire. Fire Saf. J. 2017, 89, 63-76. [CrossRef]

31. Ring, T.; Zeiml, M.; Lackner, R. Underground concrete frame structures subjected to fire loading: Part I-Large-scale fire tests. Eng. Struct. 2014, 58, 175-187. [CrossRef]

32. Ring, T.; Zeiml, M.; Lackner, R. Underground concrete frame structures subjected to fire loading: Part II-Re-analysis of large-scale fire tests. Eng. Struct. 2014, 58, 188-196. [CrossRef]

33. El-Tayeb, E.; El-Metwally, S.; Askar, H.; Yousef, A. Thermal analysis of reinforced concrete beams and frames. HBRC J. 2017, 13, 8-24. [CrossRef]

34. Blanchard, E.; Boulet, P.; Desanghere, S.; Cesmat, E.; Meyrand, R.; Garo, J.; Vantelon, J. Experimental and numerical study of fire in a midscale test tunnel. Fire Saf. J. 2012, 47, 18-31. [CrossRef]

35. Maraveas, C.; Vrakas, A. Design of concrete tunnel linings for fire safety. Struct. Eng. Int. 2014, 24, 319-329. [CrossRef]

36. Pichler, C.; Lackner, R.; Mang, H. Safety assessment of concrete tunnel linings under fire load. J. Struct. Eng. 2006, 132, 961-969. [CrossRef]

37. Feist, C.; Aschaber, M.; Hofstetter, G. Numerical simulation of the load-carrying behavior of RC tunnel structures exposed to fire. Finite Elem. Anal. Des. 2009, 45, 958-965. [CrossRef]

38. Yan, Z.G.; Zhu, H.H.; Ju, J.; Ding, W.Q. Full-scale fire tests of RC metro shield TBM tunnel linings. Constr. Build. Mater. 2012, 36, 484-494. [CrossRef]

39. Guo, J.; Jiang, S.; Zhang, Z. Fire thermal stress and its damage to subsea immersed tunnel. Procedia Eng. 2016, 166, 296-306. [CrossRef]

40. Lu, L.; Qiu, J.; Yuan, Y.; Tao, J.; Yu, H.; Wang, H.; Mang, H. Large-scale test as the basis of investigating the fire-resistance of underground RC substructures. Eng. Struct. 2019, 178, 12-23. [CrossRef]

41. Rattei, G.; Lentz, A.; Kohl, B. How frequent are fire in tunnels-Analysis from Austrian tunnel incident statistics. In Proceedings from the Seventh International Conference on Tunnel Safety and Ventilation, Graz, Austria, 12-13 May 2014; pp. 5-11.

42. ABAQUS (2016). ABAQUS Documentation; Dassault Systèmes: Vélizy-Villacoublay, France, 2016.

43. CEN. Eurocode 2: Design of Concrete Structures-Part 1-2: General rules-Structural Fire Design (EN 1992-1-2). 2005. Available online: https:/ / www.phd.eng.br/wp-content/uploads/2015/12/en.1992.1.2. 2004.pdf (accessed on 30 October 2018).

44. International Federation for Structural Concrete (FIB). FIB Model Code for Concrete Structures 2010; International Federation for Structural Concrete: Lausanne, Switzerland, 2013.

45. Bailey, C. Holistic behaviour of concrete buildings in fire. Proc. Inst. Civ. Eng.-Struct. Build. 2002, 152, $199-212$. [CrossRef]

46. Ministry of Construction of China. Standard for Test Method of Mechanical Properties on Ordinary Concrete (GB/T 50081-2002); Ministry of Construction of China: Beijing, China, 2002.

47. Ministry of Construction of China. Standard for Metro Design (GB50157-2003); Ministry of Construction of China: Beijing, China, 2003. 
48. CEN. Eurocode 2: Design of Concrete Structures-Part 1-1: General Rules and Rules for Buildings (EN 1992-1-1). 2005. Available online: https://www.phd.eng.br/wp-content/uploads/2015/12/en.1992.1.1. 2004.pdf (accessed on 30 October 2018).

49. Díaz, R. Thermomechanical Analysis of a Fire Test of a Segment of a Subway Station by Means of Three-Dimensional Finite Element Simulations. Master's Thesis, TU Wien, Vienna, Austria, 2018.

50. Lie, T.; Erwin, R. Method to calculate the fire resistance of reinforced concrete columns with rectangular cross section. ACI Struct. J. 1993, 90, 52-60.

51. American Society for Testing and Materials (ASTM). Standard Test Methods for Fire Tests of Building Construction And Materials (ASTM E119); ASTM: West Conshohocken, PA, USA, 1988.

52. American Society of Civil Engineers (ASCE). Structural Fire Protection; ASCE: Reston, VA, USA, 1982.

53. Bažant, Z.; Kaplan, M. Concrete at High Temperatures: Material Properties and Mathematical Models; Longman Group Limited: Harlow, UK, 1996.

54. Fletcher, I.; Borg, A.; Hitchen, N.; Welch, S. Performance of concrete in fire: A review of the state of the art, with a case study of the Windsor Tower fire. In Proceedings of the 4th International Workshop in Structures in Fire, Aveiro, Portugal, 10-12 May 2006.

55. Kodur, V. Properties of concrete at elevated temperatures. ISRN Civ. Eng. 2014, 2014, 1-15. [CrossRef]

56. Anderberg, Y.; Forsen, N. Fire Resistance of Concrete Structures; Division of Building Fire Safety and Technology, Lund Institute of Technology: Lund, Sweden, 1982.

57. Naus, D. The Effect of Elevated Temperature on Concrete Materials And Structures-A literature Review; U.S. Nuclear Regulatory Commission Office of Nuclear Regulatory Research Under Interagency Agreement No. 1886-N674-1Y; U.S. Nuclear Regulatory Commission: Rockville, MD, USA, 2015.

58. Ren, H. Theoretical Analysis and Fire-Resistance Design of HPC Shear Walls. Master's Thesis, Tongji University, Shanghai, China, 2006.

59. Fletcher, I.; Welch, S.; Torero, J.; Carvel, R.; Usmani, A. Behaviour of concrete structures in fire. Therm. Sci. 2007, 11, 37-52. [CrossRef]

60. Law, A. The Assessment and Response of Concrete Structures Subject to Fire. Ph.D. Thesis, University of Edinburgh, Edinburgh, Scotland, 2010.

61. Ministry of Construction of China. Practice Manual for Design of Concrete Structures (GB 50010-2002); Ministry of Construction of China: Beijing, China, 2002.

62. Achenbach, M.; Lahmer, T.; Morgenthal, G. Identification of the thermal properties of concrete for the temperature calculation of concrete slabs and columns subjected to a standard fire-Methodology and proposal for simplified formulations. Fire Saf. J. 2017, 87, 80-86. [CrossRef]

63. Felicetti, R. Assessment methods of fire damages in concrete tunnel linings. Fire Technol. 2013, 49, 509-529. [CrossRef]

64. Schlappal, T.; Schweigler, M.; Gmainer, S.; Peyerl, M.; Pichler, B. Creep and cracking of concrete hinges: Insight from centric and eccentric compression experiments. Mater. Struct. 2017, 50, 244. [CrossRef] [PubMed]

65. Wyrzykowski, M.; Lura, P. Moisture dependence of thermal expansion in cement-based materials at early ages. Cem. Concr. Res. 2013, 53, 25-35. [CrossRef]

66. Wang, H.; Binder, E.; Mang, H.; Yuan, Y.; Pichler, B. Multiscale structural analysis inspired by exceptional load cases concerning the immersed tunnel of the Hong Kong-Zhuhai-Macao Bridge. Undergr. Space 2018. [CrossRef]

67. Lubliner, J.; Oliver, J.; Oller, S.; Oñate, E. A plastic-damage model for concrete. Int. J. Solids Struct. 1989, 25, 299-326. [CrossRef]

68. Birtel, V.; Mark, P. Parameterised Finite Element modelling of RC beam shear failure. In Proceedings of the 2006 ABAQUS Users' Conference, Boston, MA, USA, 23-25 May 2006; pp. 95-108.

69. Jankowiak, T.; Lodygowski, T. Identification of parameters of Concrete Damage Plasticity constitutive model. Found. Civ. Environ. Eng. 2005, 6, 53-69.

(C) 2018 by the authors. Licensee MDPI, Basel, Switzerland. This article is an open access article distributed under the terms and conditions of the Creative Commons Attribution (CC BY) license (http://creativecommons.org/licenses/by/4.0/). 